\title{
On the Potential Predictability of Seasonal Land-Surface Climate
}

\author{
T.J. Phillips
}

October 1, 2001

U.S. Department of Energy

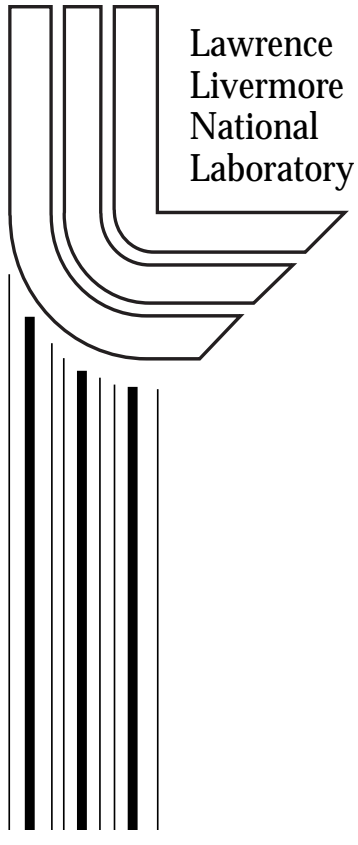




\section{DISCLAIMER}

This document was prepared as an account of work sponsored by an agency of the United States Government. Neither the United States Government nor the University of California nor any of their employees, makes any warranty, express or implied, or assumes any legal liability or responsibility for the accuracy, completeness, or usefulness of any information, apparatus, product, or process disclosed, or represents that its use would not infringe privately owned rights. Reference herein to any specific commercial product, process, or service by trade name, trademark, manufacturer, or otherwise, does not necessarily constitute or imply its endorsement, recommendation, or favoring by the United States Government or the University of California. The views and opinions of authors expressed herein do not necessarily state or reflect those of the United States Government or the University of California, and shall not be used for advertising or product endorsement purposes.

This is a preprint of a paper intended for publication in a journal or proceedings. Since changes may be made before publication, this preprint is made available with the understanding that it will not be cited or reproduced without the permission of the author. 


\title{
ON THE POTENTIAL PREDICTABILITY OF SEASONAL LAND-SURFACE CLIMATE
}

\author{
Thomas J. Phillips \\ Program for Climate Model Diagnosis and Intercomparison \\ Lawrence Livermore National Laboratory \\ Livermore, California
}

October 2001 


\begin{abstract}
The chaotic behavior of the continental climate of an atmospheric general circulation model is investigated from an ensemble of decadal simulations with common specifations of radiative forcings and monthly ocean boundary conditions, but different initial states of atmosphere and land. The variability structures of key model land-surface processes appear to agree sufficiently with observational estimates to warrant detailed examination of their predictability on seasonal time scales. This predictability is inferred from several novel measures of spatio-temporal reproducibility applied to eleven model variables. The reproducibility statistics are computed for variables in which the seasonal cycle is included or excluded, the former case being most pertinent to climate model simulations, and the latter to predictions of the seasonal anomalies. Because the reproducibility metrics in the latter case are determined in the context of a "perfectly" known ocean state, they are properly viewed as estimates of the potential predictability of seasonal climate. Inferences based on these reproduci bility metrics are shown to be in general agreement with those derived from more conventional measures of potential predictability.

It is found that the land-surface variables which include the seasonal cyde are impacted only marginally by changes in initial conditions; moreover, their seasonal dimatologies exhibit high spatial reproducibility. In contrast, the reproducibility of a seasonal land-surface anomaly is generally low, although it is considerably higher in the Tropics; its spatial reproducibility al so fluctuates in tandem with warm and cold phases of theE I Niño/Southern Oscillation phenomenon. However, the detailed sensitivities to initial conditions depend somewhat on the land-surface process: pressure and temperature anomalies exhibit the highest temporal reproducibilities, while hydrological and turbulent flux anomalies show the highest spatial reproducibilities. Implications of these results for model intercomparisons and seasonal forecasts are elaborated.
\end{abstract}




\section{Introduction}

While the implications of initial-condition sensitivity (i.e. "chaos") for the prediction of climate have been recognized for decades (e.g. Lorenz 1964, Leith 1973), practical investigation of this problem with general circulation models (GCMs) began much more recently (Chervin 1986, Zwiers 1987). Moreover, only in the past few years has computer performance advanced sufficiently to permit routine generation of experimental ensembles for studies of climate predictability on a range of time scales.

Cubasch et al. (1994), for example, showed that the multi-decadal climate simulated by a synchronously coupled ocean-atmosphere model is sensitive to the initial conditions, an issue revisited by Delworth and Knutson (2000) for transient global-warming experiments. Barnett (1995) noted that chaos is also a factor in "two-tier" experiments wherein the ocean and atmosphere models are asynchronously coupled, and Hansen et al. (1997) documented its effects at annual to decadal time scales in coupled climate-change simulations involving a mixed-layer ocean. Many other investigators (a partial list includes Palmer and Anderson 1994, Dix and Hunt 1995, Kumar and Hoerling 1995, Stern and Miyakoda 1995, Bengtsson et al. 1996, Zwiers 1996, Carson 1998, Zwiers and Kharin 1998, Wang and Zwiers 1999, Dirmeyer 2000, Koster et al. 2000, Shukla et al. 2000, and Dirmeyer et al. 2001) have conclusively demonstrated that, even when ocean boundary conditions are prescribed, simulations of climate also are highly chaotic at seasonal time scales, especially outside the Tropics.

However, many of these seasonal predictability studies have focussed on the dynamics of the free atmosphere, rather than on the processes at the land surface, the chief locus of human interaction with the climate system. Even when continental processes were considered (e.g. by Dix and Hunt 1995, Stern and Miyakoda 1995, Wang and Zwiers 1999, Koster et al. 2000, Dirmeyer 2000), only a limited number of variables (e.g. precipitation and soil moisture) were investigated. Thus, a more comprehensive assessment of the predictability of seasonal land-surface climate is called for, in light of the potentially huge societal ramifications.

It should be noted as well that the initial-condition sensitivity of continental climate is relevant for climate modeling activities that lie outside the sphere of predictability studies per se. The most clearcut examples include modeling experiments where chaos may confound attempts to attribute model variations in simulated seasonal climates to differences in coupled land-surface schemes (e.g. Henderson-Sellers et al. 1996, Polcher 2000); but such issues are also germane for virtually all model intercomparison projects that consider land-surface processes. Hence, there is an overarching need to identify when and where continental climate simulations are likely to be most "reproducible" in the context of variations in model initial conditions. 
In the present study, we infer the spatio-temporal reproducibility of a diverse collection of seasonal land-surface variables from an ensemble of decadal climate simulations implemented by a version of the European Centre for Medium-Range Weather Forecasts (ECMWF) GCM with prescribed ocean boundary conditions. We consider the reproducibility of each land-surface variable when its climatological seasonal cycle is included or excluded--configurations that are most pertinent, respectively, to model intercomparison projects and seasonal predictability studies.

In Section 2, we summarize the salient features of the ECMWF model version and of the experimental design, and in Section 3 we compare the simulated interannual variability against observational analyses, as an indication of the model's suitability for this study. In Section 4, we apply some novel measures of spatio-temporal reproducibility to the selected land-surface variables, and in Section 5 we verify that these results are comparable to those obtained from more conventional metrics. Finally, in Section 6 we elaborate on the implications of this study for both model intercomparisons and seasonal forecasts.

\section{Experimental Design}

\section{a. The model}

For this study, we employed cycle 36 of the ECMWF atmospheric GCM, a version that was in operational use during the early 1990s. In this model, the atmospheric primitive equations are represented as truncated series of spherical harmonic basis functions, where nonlinear terms and many physical parameterizations are calculated on a Gaussian grid and then transformed to the spectral space. In our experiments, the horizontal resolution was triangularly truncated at wave number 42 (corresponding to a 64 x 128 Gaussian grid), and vertical differences were expressed on 19 unevenly spaced levels in hybrid sigma-pressure coordinates. For a surface pressure of 1000 $\mathrm{hPa}$, the lowest prognostic level was at $996 \mathrm{hPa}$, and 5 levels were below $800 \mathrm{hPa}$.

The prognostic equations were solved semi-implicitly at a 30-minute time step, but with radiative fluxes (after Morcrette 1991) and clouds (after Slingo 1987) updated only every 3 hours. Convection was formulated as in Tiedtke (1989). Dissipation was implemented as biharmonic horizontal diffusion, stability-dependent second-order vertical diffusion, and orographic gravitywave drag is parameterized after Miller et al. (1989). In the surface layer, fluxes of momentum, heat, and moisture were treated as in Louis (1979), with Miller et al. (1992) modifications of stabilitydependent drag coefficients to enhance ocean surface evaporation for calm conditions.

Land-surface processes were parameterized after Blondin (1989). A vegetation canopy occupying a variable fraction of each grid box intercepted a portion of the incident precipitation, which subsequently evaporated at the potential rate. Transpiration of soil moisture was regulated 
by a canopy resistance that depended on local radiation and moisture stresses, but not on vegetation type. Evaporation and sublimation from the bare-soil and snow-covered fractions of each grid box also were treated.

Temperature and moisture were predicted by diffusion equations in top and middle soil layers (thickness $0.07 \mathrm{~m}$ and $0.42 \mathrm{~m}$, respectively), but were prescribed from monthly climatologies in an underlying deep layer. When the moisture capacity of the top soil layer $(.02 \mathrm{~m})$ was exceeded, surface runoff occurred; base flow resulted from overflow of the middle soil layer (moisture capacity 0.12 m). Further characteristics of the ECMWF (cycle 36) model are summarized by Phillips (1994).

Several potential sources of chaotic behavior may be identified in such a land-surface scheme. First, the initial specification of soil temperature/moisture and snow cover can impact the scheme's equilibrium state (Yang et al. 1995). The presence of canopy-intercepted precipitation also tends to skew the variability of the surface evaporation toward higher frequencies (Scott et al. 1997). Moreover, coupling this scheme to an atmospheric model that is also sensitive to initial conditions is likely to accentuate the overall chaotic behavior of the system.

Some problematical aspects of this land-surface scheme for inferring the reproducibility of continental climate also should be mentioned. The most significant drawback is the use of a climatological soil layer, which fails to ensure conservation of energy and moisture, since a zero-flux condition is not imposed at the lower boundary of the soil column. This and other shortcomings (e.g. as noted by Betts et al. 1993) have motivated revisions of the land-surface parameterizations in subsequent versions of the ECMWF model (Viterbo and Beljaars 1995, Beljaars et al. 1996).

\section{b. The ensemble experiments}

An ensemble of 6 decadal climate simulations were generated, where each realization had common ocean boundary conditions that included Atmospheric Model Intercomparison Project (AMIP) specifications of observed monthly sea surface temperatures (SSTs) and sea ice extents for the period 1 January 1979 to 31 December 1988 (Gates 1992, Gates et al. 1999). (These boundary conditions were updated daily by linear interpolation of contiguous monthly fields.) In addition,

common AMIP values of the solar constant $\left(1365 \mathrm{~W} \mathrm{~m}^{-2}\right)$ and the carbon dioxide concentration (345 ppm) were specified.

The nominal start time of each realization was also the same (00 GMT on 1 January 1979), but the initial conditions of atmosphere and land differed. For the first realization, the initial conditions were specified from the ECMWF observational analysis for 00 GMT on 15 January 1979 (taken as the effective date of the monthly mean January 1979 AMIP SST and sea ice extents). For each of the 5 companion realizations, a different initial state that also was 
representative of January climate was imposed, for example, by specifying the initial conditions (at 00 GMT on 1 January 1979) for a new simulation to be the same as the state at the last time step (i.e., at 23:30 GMT on 31 December 1988) of a companion simulation.

\section{The Simulated Surface Climate}

\section{a. Model data}

For each decadal realization, we computed time series of 120 monthly averages of 11 AMIP "standard output variables" (Gates 1992) that provided a fairly comprehensive portrait of the simulated surface climate (Table 1). We also calculated time series of the seasonal averages of these variables, i.e. for each sample of March-April-May (MAM), June-July-August (JJA), SeptemberOctober-November (SON), and December-January-February (DJF) climates. (Owing to the simulation start date on 1 January 1979, only 9 samples of DJF climates were available, resulting in a time series of 39 seasonal samples per decadal realization.)

As expected, these seasonal averages were less sensitive to initial conditions than were the monthly means, since longer time-averaging filters out more of the climate noise engendered by the chaotic daily weather systems (Leith 1973, Barnston 1994). Averaging over periods longer than a season would further decrease the level of climate noise (Ebisuzaki 1995, Chen and van den Dool 1997), but at the expense of reducing the number of samples available from the decadal simulations. We thus limited our analysis to seasonal time scales.

\section{b. Validation of model variability}

The accuracy to which the reproducibility of seasonal land-surface climate can be estimated from ensemble experiments depends on how well the model reproduces the observed interannual variability (Kumar et al. 1996, Sperber and Palmer 1996, Liang et al. 1997). Hence, as a preliminary check of the model, we compare the seasonal interannual variability of 3 key seasonal variables--sea-level pressure (psl), surface air temperature (tas), and precipitation (pr)--against the corresponding NCEP-NCAR reanalysis products over the 1979-1988 decade (Kalnay et al. 1996). (For reasons that will become clearer in Section 5, our choice of the NCEP-NCAR reanalysis as a model validation reference is primarily because it provides a comprehensive and self-consistent picture of surface climate variability during the AMIP period 1979-1988, and not necessarily because it affords the "best" estimate of variability for any single process.)

Comparison maps are shown for JJA and DJF in Figures 1-3. From Figure 1, it is seen that the simulated interannual variability of sea-level pressure is generally in good agreement with the 
reanalysis. The chief discrepancies include too little variability near Antarctica in JJA (Figure 1a vs 1b) and over the Northern Atlantic/European sector in DJF (Figure 1c vs 1d).

For surface air temperature in JJA, the centers of variability are about the same magnitude as in the reanalysis, although their position and extent are somewhat different (Figure $2 \mathrm{a}$ vs $2 \mathrm{~b}$ ). In DJF, however, the model's variability is systematically lower than that of the reanalysis over the Northern continents (Figure 2c vs 2d).

The magnitude and pattern of the model's precipitation variability is quite similar to that of the reanalysis in midlatitudes, especially in JJA (Figure 3a vs 3b); however, the simulated variability is generally too large over the tropical oceans, as well as over southern Asia during JJA. Here the discrepancies may largely reflect the different convective schemes of the ECMWF and NCEP reanalysis models (Tiedtke 1989, Pan and Wu 1994).

In summary, the ECMWF model seems to produce a generally credible simulation of the interannual variability of these key surface variables, especially over land. However, there are some apparent shortcomings in simulating details of this variability in certain regions and seasons.

\section{Reproducibility of Model Land-Surface Variables}

\section{a. Measures of spatio-temporal reproducibility}

To quantify the spatio-temporal reproducibility of a variable $\mathbf{V}$, we compute temporal and spatial (pattern) correlations between all the independent pairs of realizations that are available from the ensemble (Santer 1988). That is, at each grid point ( $i, j$ ) we calculate zero-lag temporal correlations $\mathbf{r}$ between each independent pair $(1, \mathrm{~m})$ of realizations of $\mathbf{V}$ :

$$
\mathbf{r}(\mathrm{i}, \mathrm{j}, \mathrm{l}, \mathrm{m})=\sum_{\mathrm{k}}^{\mathrm{K}}\{\mathbf{V}(\mathrm{i}, \mathrm{j}, \mathrm{k}, \mathrm{l})-\overline{\mathbf{V}}(\mathrm{i}, \mathrm{j}, \mathrm{l})\} *\{\mathbf{V}(\mathrm{i}, \mathrm{j}, \mathrm{k}, \mathrm{m})-\overline{\mathbf{V}}(\mathrm{i}, \mathrm{j}, \mathrm{m})\} /\left\{\mathrm{K} * \sigma_{\mathrm{t}}(\mathrm{i}, \mathrm{j}, \mathrm{l}) * \sigma_{\mathrm{t}}(\mathrm{i}, \mathrm{j}, \mathrm{m})\right\}
$$

Here $\overline{\mathbf{V}}$ denotes the time average of $\mathbf{V}$ and $\sigma_{\mathbf{t}}$ is its temporal standard deviation; the summation is over all $\mathrm{K}=39$ seasonal samples $\mathrm{k}$ in a decadal realization. As a measure of the spatial reproducibility of each seasonal sample $\mathrm{k}$, we compute pattern correlations $\mathbf{s}$ between each independent pair $(\mathrm{l}, \mathrm{m})$ of realizations of $\mathbf{V}$ :

$$
\mathbf{s}(\mathrm{k}, \mathrm{l}, \mathrm{m})=\sum_{\mathrm{i}, \mathrm{j}}^{\mathrm{IxJ} J}\{\mathbf{V}(\mathrm{i}, \mathrm{j}, \mathrm{k}, \mathrm{l})-[\mathbf{V}(\mathrm{k}, \mathrm{l})]\} *\{\mathbf{V}(\mathrm{i}, \mathrm{j}, \mathrm{k}, \mathrm{m})-[\mathbf{V}(\mathrm{k}, \mathrm{m})]\} /\left\{(\mathrm{Ix} \mathrm{J}) * \sigma_{\mathbf{s}}(\mathrm{k}, \mathrm{l}) * \sigma_{\mathbf{s}}(\mathrm{k}, \mathrm{m})\right\}
$$

Here [V] denotes the spatial average of $\mathbf{V}$ and $\sigma_{\mathbf{S}}$ is its spatial standard deviation; the summation is over the total number I x J of surface grid points $(\mathrm{i}, \mathrm{j})$ for the chosen 64 x 128 Gaussian grid, or $~ 2500$ grid points when only land surfaces are considered. 
For an ensemble of $\mathrm{n}$ model experiments, the number $\mathrm{N}$ of independent pairs $(1, \mathrm{~m})$ of realizations is given by

$$
\mathrm{N}=\mathrm{n} ! /\{2 !(\mathrm{n}-2) !\}
$$

In our study, the ensemble of $n=6$ realizations yields $N=15$ samples of $\mathbf{r}$ and $\mathbf{s}$, thereby capturing essentially all the available information on the spatio-temporal reproducibility of $\mathbf{V}$. As an overall measure of reproducibility, we calculate the mean $\mu$ and the scatter $\delta$ among these $\mathrm{N}$ samples. For example, in the case of measure $\mathbf{r}$,

$$
\begin{aligned}
& \mu\{\mathrm{r}(\mathrm{i}, \mathrm{j})\}=\sum_{1, \mathrm{~m}}^{\mathrm{N}} \mathrm{r}(\mathrm{i}, \mathrm{j}, 1, \mathrm{~m}) / \mathrm{N} \\
& \delta\{\mathrm{r}(\mathrm{i}, \mathrm{j})\}=\left\{\sum_{1, \mathrm{~m}}^{\mathrm{N}}(\mathrm{r}(\mathrm{i}, \mathrm{j}, 1, \mathrm{~m})-\mu\{\mathrm{r}(\mathrm{i}, \mathrm{j})\})^{2} / \mathrm{N}\right\}^{1 / 2}
\end{aligned}
$$

\section{b. Reproducibility of the seasonal variables}

We first consider a surface variable that includes the seasonal cycle--common practice in climate model intercomparison projects. In this context, $\mathbf{r}$ and $\mathbf{s}$ essentially measure the reproducibility of the variable's seasonal cycle, which accounts for nearly all of the spatiotemporal variance about the decadal mean.

\section{Temporal reproducibility}

As an example of the temporal reproducibility of a model variable, maps of $\mu\{\mathbf{r}(\mathrm{i}, \mathrm{j})\}$ and $\delta\{\mathbf{r}(\mathrm{i}, \mathrm{j})\}$ for the simulated seasonal precipitation are shown in Figure 4. These display some pronounced latitudinal asymmetries: the highest mean correlations $\mu\{\mathbf{r}(\mathrm{i}, \mathrm{j})\}>0.9$ occur in the Tropics, where barotropic atmospheric dynamics tend to mitigate against chaotic fluctuations. Here, the high-correlation areas include continental regions in Amazonia, equatorial Africa, and southeast Asia. However, at most extratropical locations where baroclinic dynamics prevail, $\mu\{\mathbf{r}(\mathrm{i}, \mathrm{j})\}<0.7$, implying that one realization of extratropical seasonal precipitation typically explains less than half the temporal variance of another. In general, the cross-realization scatter $\delta\{\mathbf{r}(\mathrm{i}, \mathrm{j})\}$ also is substantially higher outside the Tropics. (This measure is not meaningful, however, where precipitation is scant, such as in northern Africa.) Some ocean-land contrasts in the temporal reproducibility of model precipitation also are evident even in the deep Tropics: mean correlations $\mu\{\mathbf{r}(\mathrm{i}, \mathrm{j})\}$ exceeding 0.9 cover broad swaths of the equatorial Atlantic and Pacific, but only portions of the adjacent continents. 
An aggregate measure of the continental temporal reproducibility of the seasonal cycle of model surface variable $\mathbf{V}$ is provided by the spatial average $\mathbf{R}$ of each sample of the cross-realization correlation $\mathbf{r}(\mathrm{i}, \mathrm{j})$ over all land points. The mean $\mu\{\mathbf{R}\}$ and scatter $\delta\{\mathbf{R}\}$ among the $\mathrm{N}=15$ realizations of each seasonal land-surface variable are depicted in Figure 5a. The temporal reproducibility of the land-surface variables ranges rather widely, with the ground and surface air temperatures (tg and tas) showing the highest values of $\mu\{\mathbf{R}\}$, and precipitation (pr) the lowest. While the intraensemble scatter $\delta\{\mathbf{R}\}$ (gray bars) is comparatively small for all the land-surface variables, it also tends to increase as $\mu\{\mathbf{R}\}$ decreases. Thus, these summary statistics present a consistent picture of the variations in temporal reproducibility displayed by model land-surface variables that include the seasonal cycle.

In Figure $5 b$, the $\mu\{\mathbf{R}\}$ and $\delta\{\mathbf{R}\}$ statistics are displayed for monthly mean samples of the same land-surface variables with the annual cycle included. As mentioned in Section 3a, the monthly landsurface variables all exhibit somewhat less temporal reproducibility than at the seasonal time scale (Figure 5a), owing to the comparatively greater sensitivity of the monthly statistics to varying initial conditions. This behavior appears to be especially pronounced for land-surface precipitation (pr).

\section{Spatial reproducibility}

The spatial reproducibility of simulated land-surface variables that include the seasonal cycle, as exemplified by the variation of the mean cross-realization pattern correlation $\mu\{\mathbf{s}(\mathrm{k})\}$ for precipitation, shows substantial variation with season $\mathrm{k}$ (Figure 6). Over land, $\mu\{\mathbf{s}(\mathrm{k})\}$ displays a pronounced sawtooth fluctuation each year (Figures 6b, 6c), with maxima repeatedly occurring in JJA and DJF and minima in MAM and SON. (The modest scatter $\delta\{\mathbf{s}(\mathrm{k})\}$ indicates that each realization shows a similar tendency for maximum spatial reproducibility in the extreme seasons.) Sawtooth fluctuations also characterize the $\mu\{\mathbf{s}(\mathrm{k})\}$ time series for global precipitation (Figure 6a), except in 1983 and 1987 when this pattern is disrupted, possibly related to incidences of El Niños in these years (see Section 4c). In addition, some interannual modulation of the amplitude of $\mu\{\mathbf{s}(\mathrm{k})\}$ can be seen for both global and continental precipitation, but the average pattern correlation is greatest for tropical land points (Figure 6c).

Time series of $\mu\{\mathbf{s}(\mathrm{k})\}$ exhibit the same behavior for all the other land-surface variables except soil moisture, which instead peaks in MAM and SON each year (not shown). Nonetheless, it is physically reasonable that the time series of this storage variable should be in quadrature with that of precipitation, signifying soil moisture's potential as a predictor of seasonal climate (e.g. Huang et al. 1996). 


\section{Spatial reproducibility of seasonal climatologies}

Because model intercomparison projects often are limited to analysis of single realizations of participating models' climates, it is relevant to consider the reproducibility of the ECMWF surface variables' seasonal climatologies (i.e., the decadal-mean MAM, JJA, SON, and DJF climates). We did so by computing the mean and scatter of the spatial pattern correlations between the $\mathrm{N}=15$ independent pairs of realizations of the seasonal climatology of a surface variable $\mathbf{V}$ that were available. For all variables and seasons, the resulting mean correlations were $\sim 1$, and their scatter less than $\sim 0.03$. We conclude that the intercomparison of single realizations of seasonal surface climatologies from a collection of GCMs with common ocean boundary conditions and radiative forcings is indeed likely to be a meaningful exercise.

\section{c. Reproducibility of seasonal anomalies}

From the standpoint of seasonal prediction, it is the reproducibility of the departures of surface variable $\mathbf{V}$ from its climatological seasonal cycle which is of interest. That is, the state of $\mathbf{V}$ in a particular season is assumed predictable to the extent that its seasonal anomalies are reproducible; otherwise, the seasonal climatology offers a better prediction. However, because the ECMWF model's ocean state is not prognostically determined, these reproducibility measures allow only the inference of a variable's potential predictability (hereafter, PP), a presumed upper bound on the operational forecast skill (Madden 1981)

Thus, to infer the PP of seasonal surface variable $\mathbf{V}$ we remove the ten-year climatological seasonal cycle from its time series, and then compute the cross-correlations $\mathbf{r}$ and $\mathbf{s}$ of the resulting seasonal anomaly $\mathbf{A}$ for each independent pair of realizations. As summary measures, we again also calculate $\mu$ and $\delta$ statistics from the $\mathrm{N}=15$ independent samples of $\mathbf{r}$ and $\mathrm{s}$.

\section{Temporal reproducibility of seasonal anomalies}

As examples of this procedure, maps of the mean cross-realization correlation $\mu\{\mathbf{r}(\mathrm{i}, \mathrm{j})\}$ and its scatter $\delta\{\mathbf{r}(\mathrm{i}, \mathrm{j})\}$ for seasonal anomalies of surface air temperature are displayed in Figure 7. Given the prescribed ocean state, it is not surprising that the anomalies of marine surface air temperature show good temporal reproducibility (i.e., high $\mu\{\mathbf{r}(\mathrm{i}, \mathrm{j})\}$ and low $\delta\{\mathbf{r}(\mathrm{i}, \mathrm{j})\}$ ). There also are a few continental locations--e.g. parts of Amazonia, equatorial Africa, and southeast Asia-where the temporal reproducibility is comparatively high. However, over most of the land surface each realization explains, on average, less than $25 \%$ of the interannual variance of another (i.e. $\mu\{\mathbf{r}(\mathrm{i}, \mathrm{j})\}<0.5$ ); moreover, the cross-realization scatter $\delta\{\mathbf{r}(\mathrm{i}, \mathrm{j})\}$ mostly exceeds 0.1 . A qualitatively similar pattern is displayed by the anomalies of ground temperature and of the 
net fluxes of surface shortwave and longwave radiation (not shown). Apparently the model's radiative/thermal anomalies are temporally reproducible to a substantial extent at only a few continental locations in the deep Tropics.

This assessment is even more appropriate for the seasonal anomalies of continental precipitation, which display generally lower values of $\mu\{\mathbf{r}(\mathrm{i}, \mathrm{j})\}$ and higher values of $\delta\{\mathbf{r}(\mathrm{i}, \mathrm{j})\}$ (Figure 8). Other hydrological variables (e.g. surface evaporation and soil moisture), as well as the surface sensible heat flux, exhibit similar behaviors (not shown). These results also are in general agreement with studies of PP of a more limited set of land-surface variables in other models (e.g. Dirmeyer et al. 2001).

More geographically widespread temporal reproducibility is evinced by the anomalies of continental sea-level pressure (Figure 9): $\mu\{\mathbf{r}(\mathrm{i}, \mathrm{j})\}$ values in excess of 0.3 extend farther poleward than for any other surface field considered, e.g. to western North America and northern parts of Australia. The cross-realization scatter $\delta\{\mathbf{r}(\mathrm{i}, \mathrm{j})\}$ also is generally less than that for other land-surface anomalies.

An overall summary of the temporal reproducibility of each land-surface anomaly variable is provided by the mean $\mu\{\mathbf{R}\}$ and scatter $\delta\{\mathbf{R}\}$ for land-averages $\mathbf{R}$ of $\mathbf{r}(\mathrm{i}, \mathrm{j})$, which are depicted in Figure 10. The highest all-land mean correlations $\mu\{\mathbf{R}\}$ are displayed by the anomalies of sea-level pressure (psl), surface air temperature (tas), and ground temperature (tg), and the lowest correlations by the anomalies of surface evaporation (evs), precipitation (pr), and sensible heat flux (hfls). Allland values of $\mu\{\mathbf{R}\}$ are generally much lower for the anomalies of Figure 10a than for the corresponding surface variables which include the seasonal cycle (Figure 5a). The all-land scatter $\delta\{\mathbf{R}\}$ of the anomalies (gray bars) in Figure 10a is also a larger fraction of $\mu\{\mathbf{R}\}$ than in Figure 5a, especially for the precipitation (pr), evaporation (evs), and sensible heat flux (hfls). The relative positions of the surface anomalies in descending order of their all-land $\mu\{\mathbf{R}\}$ also differ in Figures 10a versus 5a, with the greatest dissimilarities being displayed by sea-level pressure (psl).

For every model surface anomaly, however, the tropical-land average $\mu\{\mathbf{R}\}$ is substantially higher, and its scatter $\delta\{\mathbf{R}\}$ lower, than the corresponding all-land statistics (compare Figures 10a and 10b). Especially noteworthy are the sea-level pressure (psl) and surface air temperature (tas), whose tropical-land $\mu\{\mathbf{R}\}$ exceed 0.40 with low scatter $\delta\{\mathbf{R}\}$. On the other hand, the relatively low tropicalland $\mu\{\mathbf{R}\}$ and high $\delta\{\mathbf{R}\}$ of precipitation (pr), soil moisture (mrso), and surface evaporation (evs) is discouraging, in view of the socio-economic import of these hydrological variables.

\section{Spatial reproducibility of seasonal anomalies}

The time series of mean cross-realization pattern correlation $\mu\{\mathbf{s}(\mathrm{k})\}$ for anomalies of precipitation (Figure 11) and sea-level pressure (Figure 12) bracket the range of spatial reproducibilities exhibited by the model's seasonal surface variables. For instance, there are many 
seasons $\mathrm{k}$ when $\mu\{\mathrm{s}(\mathrm{k})\}$ for the global precipitation anomalies is $>0.5$ (Figure 11a), but only a few cases of comparable mean pattern correlations for the pressure anomalies (Figure 12a). There also is much less scatter $\delta\{\mathbf{s}(\mathrm{k})\}$ in the time series of the precipitation anomalies (compare separation of dashed and solid lines in Figures 11 and 12), apparently because their spatial patterns are more consistent across realizations than those of the pressure anomalies.

However, the spatial reproducibility of the precipitation anomalies is substantially reduced over land (compare Figures 11a and 11b), especially in middle and high latitudes (compare Figures $11 \mathrm{~b}$ and 11c). The continental sea-level pressure anomalies also are much less spatially reproducible outside the Tropics (compare Figures 12b and 12c); however, in contrast to global precipitation (Figure 11a), the $\mu\{\mathbf{s}(\mathrm{k})\}$ of the pressure anomalies increase only marginally when ocean points are included in the calculations (compare Figures 12a and 12b). (A selective comparison of maps of the six realizations of sea-level pressure anomalies at particular years/seasons indicated that pattern differences were especially pronounced in polar latitudes.)

From Figures 11 and 12, it is evident that the spatial reproducibility of the seasonal anomalies fluctuates markedly in time. The largest peaks in $\mu\{\mathrm{s}(\mathrm{k})\}$ coincide with occurrences of El Niños in 1982/83 and 1986/87; in some cases, smaller peaks occur at times of La Niñas in 1984/85 (Figures 11a and 11c) and in the latter part of 1988 (Figures 11a and 12c). At such times, the reproducibility of the continental anomalies is more pronounced in the Tropics (Figures 11c and 12c), but a substantial extratropical signal in MAM 1983 is associated with the exceptionally intense 1982/83 El Niño (Figures 11b and 12b). Other investigators (e.g., Brankovic et al. 1994, Anderson and Stern 1996, Bengtsson et al. 1996, Zwiers 1996) also have noted a propensity for global predictability to peak in the MAM season following onset of an El Niño in the latter part of the previous year. The timing is thought to be related to the maximal extent of tropical SSTs exceeding $28 \mathrm{deg} \mathrm{C}$ (a threshold for convection), and a dynamical basic state that expedites tropicalextratropical interactions (Hoerling et al. 1995, Higgins and Halpert 1997, Sud et al. 1999).

Figure 13 displays the MAM 1983 ensemble-mean anomaly fields (averaged across the 6 model realizations) of sea-level pressure, surface air temperature, and precipitation. Shaded areas indicate where these anomalies are significantly different (at the $95 \%$ confidence level) from other MAM seasons in years without El Niños--that is, in all other years of the simulation decade except 1987. (The significance test utilizes a nonparameteric Kolmogorov-Smirnov statistic that is especially suited for non-Gaussian variables such as precipitation--see Anderson and Stern 1996.)

Several significant anomalies commonly associated with El Niños (e.g. Quiroz 1983, Ropelewski and Halpert 1987, Barnett 1988, Kiladis and Diaz 1989, Kane 1997) are present in Figure 13. These include pronounced Southern Oscillation and North Pacific pressure anomalies (Figure 13a); anomalous warming of tropical continents and of northern/western North America, with cooling 
of boreal continental interiors (Figure 13b); and abnormally wet/dry conditions in the eastern/western tropical Pacific (Figure 13c). (The canonical precipitation anomaly centered in the southeastern U.S. during El Niños is more evident in the analogous map for the preceding DJF season, not shown here.) The temperature anomalies (Figure 13b) are most widespread over the extratropical continents, and the precipitation anomalies (Figure 13c) are least so, but the latter are more extensive in this season than is the model norm (e.g. Figure 8).

Figure 14 depicts the overall spatial reproducibility of the model land-surface anomalies. Summary statistics include the mean and scatter $\mu\{\mathbf{S}\}$ and $\delta\{\mathbf{S}\}$ of the time-average $\mathbf{S}$ of the series of cross-realization pattern correlations $\mathrm{s}(\mathrm{k})$, season $\mathrm{k}=1, \ldots, 39$, that are computed alternatively over all-land (Figure 14a) and tropical-land points (Figure 14b). The mean and scatter $\mu\{\mathbf{M}\}$ and $\delta\{\mathbf{M}\}$ in the maximum $\mathbf{M}$ of each all-land and tropical-land time series $\mathbf{s}(\mathrm{k})$ also is displayed in Figures $15 \mathrm{a}$ and $15 \mathrm{~b}$, respectively.

In contrast to their relatively high temporal reproducibility (Figure 10a), the all-land sea-level pressure (psl) anomalies exhibit the least spatial reproducibility (lowest $\mu\{\mathbf{S}\}$ and highest $\delta\{\mathbf{S}\}$ ) of any surface variable (Figure 14a). The ground and surface air temperature anomalies (tg and tas) display similar tendencies; conversely, anomalies of precipitation (pr), evaporation (evs), and sensible heat flux (hfss) show relatively high spatial reproducibility, but low temporal reproducibility. This apparent spatio-temporal asymmetry may be physically based (e.g. indicating that the continental pr, evs, and hfss anomalies are more likely to occur in certain locations), or at least may be indicative of present-day GCM land-surface simulations (e.g. Phillips et al. 2000). However, this asymmetry also may partly reflect differences in statistical sampling, in that $\mathbf{R}$ is a spatial average over several thousand grid points, while $\mathbf{S}$ is a temporal average over just 39 seasonal samples. Because $\mathbf{R}$ thus is likely to be more statistically robust than $\mathbf{S}$, the summary information in Figure 10 probably should be emphasized over that of Figure 14 for purposes of ranking the overall reproducibility of the model's land-surface anomalies. (Nonetheless, if these preliminary indications of higher spatial reproducibility of the hydrological variables and turbulent fluxes are borne out in other predictability studies, this could have considerable utility in operational seasonal forecasting.)

From a comparison of $\mu\{\mathbf{S}\}$ and $\delta\{\mathbf{S}\}$ over only tropical land points (Figure 14b), it is seen that the relatively low all-land spatial reproducibility of certain model anomalies mainly owes to their behavior over extratropical continents. This tropical-extratropical asymmetry in pattern correlations is especially striking for the sea-level pressure (psl) anomaly, but is also clearcut for soil moisture mrso, radiant fluxes rss and rls, and surface wind stresses tauu and tauv. Similarly, the mean maxima $\mu\{\mathbf{M}\}$ of the tropical-land $\mathbf{s}(\mathrm{k})$ time series (Figure $15 \mathrm{~b}$ ) are substantially higher than those for all-land points (Figure 15a). Nonetheless, the timing of $\mu\{\mathbf{M}\}$ for most anomalies coincides with 
the intense 1982/83 El Niño (designated by bracketed anomaly labels in Figures 15a,b), irrespective of whether the pattern correlations include all-land or only tropical-land points.

\section{Comparisons With Conventional Measures of Predictability}

The mean correlations $\mu\{\mathbf{r}(\mathrm{i}, \mathrm{j})\}$ and $\mu\{\mathbf{s}(\mathrm{k})\}$ are likely to be comparatively robust measures of reproducibility since, for the given ensemble size $n=6$, they are derived from $N=15$ independent samples of $\mathbf{r}$ and $\mathbf{s}$. However, $\mathbf{r}$ and $\mathbf{s}$ themselves are computed from gridded seasonal data that are not statistically independent, since they are serially/spatially correlated with data at neighboring seasons and grid points. This complicates the estimation of threshold values of $\mathbf{r}$ or $\mathbf{s}$ that would signify the likely presence of PP. Although such thresholds could be empirically determined, for example by use of resampling techniques, the resulting criteria would be variable-specific (e.g. Livezey and Chen 1983). As an alternative, we will show that inferences of PP based on $\mathbf{r}$ and $\mathbf{s}$ compare well with conventional measures of predictability having more clearcut thresholds.

Here we present the results of applying two such measures: a fractional variance statistic $\mathbf{f}$ and a forecast skill score $\mathbf{c}$ derived from the spatial pattern correlation of simulated vs. observed anomalies. Note, however, that these metrics both are obtained at the cost of reducing the effective sample size from $\mathrm{N}=15$ to $\mathrm{n}=6$.

\section{a. Fractional variance measure}

The fractional variance measure $\mathbf{f}$ is an estimate of the portion of the total variability $\sigma_{\mathbf{T}}{ }^{2}$ of climate variable $\mathbf{V}$ that is attributable to the ocean boundary forcing ${\sigma_{\mathbf{B}}}^{2}$, as opposed to the internal variability ${\sigma_{\mathbf{I}}}^{2}$ that is assumed to be unpredictable (Madden 1981):

$$
\begin{gathered}
\mathbf{f}=\sigma_{\mathbf{B}}{ }^{2} /{\sigma_{\mathrm{T}}}^{2} \\
\text { where } \\
{\sigma_{\mathrm{T}}}^{2}={\sigma_{\mathbf{B}}}^{2}+{\sigma_{\mathrm{I}}}^{2}
\end{gathered}
$$

In this framework, a conservative threshold that implies the likely presence of $\mathbf{P P}$ is ${\sigma_{\mathbf{B}}}^{2}>{\sigma_{\mathbf{I}}}^{2}$, or $\mathbf{f}>0.5$. Analogous to the temporal reproducibility $\mathbf{r}$, the statistic $\mathbf{f}$ is computed at each grid point $(\mathrm{i}, \mathrm{j})$; in addition, $\mathbf{f}$ usually is determined as a function of climatological season $\tau$ (i.e. MAM, JJA, SON, and DJF), thereby allowing investigation of putative seasonal variations in PP. 
Following Kumar and Hoerling (1995), we estimated ${\sigma_{\mathbf{B}}}^{2}$ from the ensemble-mean interannual variability of $\mathbf{V}$ in season $\tau$, and ${\sigma_{\mathbf{I}}}^{2}$ from the intraensemble variability of the different model realizations of season $\tau$, where in both cases the sample size is $n=6$. Maps of $\mathbf{f}$ (Figure 16) suggest that the inferred PP of the model's sea-level pressure displays greater extratropical extent than that of other land-surface variables, notably over western North America during JJA and over Australia during DJF. The surface air temperature also exhibit apparent $\mathbf{P P}$ over parts of North America in MAM (Figure 17), a pattern reminiscent of what Zwiers (1996) reported for the $850 \mathrm{hPa}$ temperature field in another model. More typical of the land-surface variables, however, are the maps of $\mathbf{f}$ for precipitation (not shown), which show very little evidence of PP outside the deep Tropics. Thus, inferences of $\mathbf{P P}$ derived from $\mathbf{f}$ are very similar to those determined from the temporal reproducibility statistic $\mathbf{r}$ (see Figures 7-9)

\section{b. Forecast skill measure}

In operational forecasting, a common measure of predictive skill is the spatial pattern correlation $\mathbf{c}$ of the simulation with observational estimates. For each of the $\mathrm{k}=39$ seasons in the AMIP decade, we computed the pattern correlation $\mathbf{c}(\mathrm{k})$ of the ensemble-mean anomaly $\mathbf{A}$ of each surface variable against a single realization of the observed anomaly, as approximated by NCEPNCAR reanalysis data (Kalnay et al. 1996) over the same time period. (The ensemble-mean anomaly being the most likely prediction of the observed climate.) Following Zwiers (1996), we also estimated the uncertainty in $\mathbf{c}(\mathrm{k})$ as the average scatter among the correlations of the 6 realizations of $\mathbf{A}$ with the reanalysis.

Plots of $\mathbf{c}(\mathrm{k})$ and its average scatter are displayed for sea-level pressure and precipitation in Figures 18 and 19, respectively. The threshold $\mathbf{c}(\mathrm{k})=0.50$ (denoted by dot-dash lines in these figures) indicates a minimum level of effective forecast skill, in the sense that the prediction may be of some practical value (Kumar and Hoerling 1995). By this criterion, effectively skillful seasonal forecasts of both global and all-land sea-level pressure occur in only a few seasons during the AMIP decade (Figures 18a, b). The prediction of continental pressure is more frequently skillful in the Tropics, sometimes for several seasons in a row (Figure 18c), but even here there are wide inter-seasonal swings in $\mathbf{c}(\mathrm{k})$, with a number of negative-valued correlations. (The $\mathbf{c}(\mathrm{k})$ skill statistic is known to be quite "unforgiving", often yielding negative values.) The $\mathbf{c}(\mathrm{k})$ for global precipitation are all positive-valued, but there is only a single instance of an effectively skillful forecast (Figure 19a). There are no effectively skillful predictions of continental precipitation, however, even when evaluation is limited to the Tropics (Figure 19b, c). 
The contrast between the more frequently skillful but "erratic" pressure correlations and the less skillful but "consistent" precipitation correlations is captured by the time-mean $\mathbf{C}$ and the maximum $\mathbf{M}$ of the respective time series $\mathbf{c}(\mathrm{k})$. The all-land and tropical-land values of $\mathbf{C}$, together with its estimated uncertainty is displayed for the 11 model surface anomalies in Figures 20a and b, while the corresponding maxima $\mathbf{M}$ are shown in Figures 21a and $\mathrm{b}$. It is seen that the all-land $\mathbf{c}(\mathrm{k})$ time series for the sea-level pressure (psl) anomaly exhibits the lowest mean $\mathbf{C}$, but the highest maximum $\mathbf{M}$ (Figures 21a and b, respectively). The uncertainty in all-land $\mathbf{C}$ for the psl anomaly is also comparatively very large, especially relative to the magnitude of $\mathbf{C}$ (Figure 20a). In contrast, the allland $\mathbf{c}(\mathrm{k})$ series for the precipitation (pr) anomaly has a low maximum $\mathbf{M}$, but the highest mean $\mathbf{C}$, along with a relatively low uncertainty. These results are reminiscent of the summary statistics of spatial reproducibility of the surface anomalies in Figure 14, where the all-land mean $\mu\{\mathbf{S}\}$ of the time series $\mathbf{s}(\mathrm{k})$ is largest for precipitation and smallest for sea-level pressure, and where there is substantially more scatter $\delta\{\mathbf{S}\}$ in the latter case.

In Figure 20a, the all-land $\mathbf{C}$ statistics for precipitation and sea-level pressure bracket the range of values for the other surface anomalies: relatively high $\mathbf{C}$ values are displayed by soil moisture (mrso) and the net shortwave/longwave radiative fluxes (rss/rls), relatively low values by the northward wind stress (tauv) and ground temperature (tg), and intermediate values by the remainder of the anomalies. There also is a sharper differentiation in the all-land $\mathbf{M}$ statistics among the surface anomalies (Figure 21a): besides psl, only the ground and surface air temperatures (tg and tas) show evidence of effective forecast skill $(\mathbf{M}>0.50)$.

Over the tropical continents, $\mathbf{C}$ increases from its all-land value for every surface anomaly (compare Figures 20a and b). The increase is proportionately greater for ground and surface air temperatures (tg and tas), for the surface wind stresses (tauu and tauv), and especially for sealevel pressure (psl), where $\mathbf{C}$ shifts from the lowest all-land value to the highest tropical-land value. For most land-surface anomalies, the maximum $\mathbf{M}$ of the tropical-land $\mathbf{c}(\mathrm{k})$ time series (Figure 21b) also exceeds its all-land value (Figure 21a), but $\mathbf{M}>0.50$ only for the tropical-land tas, tauu, and psl anomalies.

It is also noteworthy that the relative ranking of the all-land anomalies in Figure 20a (in descending order of all-land $\mathbf{C}$ values) roughly corresponds to that derived from the all-land $\mu\{\mathbf{S}\}$ values of Figure 14a. However, the impact of the 1982/83 El Niño on the maxima M of the landsurface correlations $\mathbf{c}(\mathrm{k})$ is reduced (compare the number of bracketed anomaly labels in Figures 15a,b versus Figures 21a,b): it is limited mainly to precipitation (pr) and soil moisture (mrso). (The maxima $\mathbf{M}$ of the $\mathbf{c}(\mathrm{k})$ time series of other land-surface variables occur in various seasons/years, only some of which correspond to ENSO events. ) 
The contrasting behaviors illustrated by Figures 14/15 versus Figures 20/21 highlight the differences between predictability statistics that are model-dependent (e.g. r, R, s, S, and f) and those more demanding metrics that reference validation data external to the model (e.g. c, $\mathbf{C}$, and M). However, to attribute the causes of all the differences between Figures 14/15 and Figures 20/21 to model shortcomings seems quite unjustified, especially for land-surface processes such as turbulent fluxes and soil moisture that are mainly determined by the parameterizations of the reanalysis model, or that may be biased by the particular assimilation/nudging techniques employed (M. Kanamitsu, personal communication). It should be acknowledged as well that validation of model predictions against observations is an inherently probabilistic exercise, since nature only provides a single realization of the observed climate, which need not correspond to the ensemble-mean state of even a hypothetically "perfect" model.

\section{Discussion}

In this study we have analyzed the initial-condition sensitivity of 11 seasonal surface variables in an ensemble of 6 ECMWF (cycle 36) model simulations of decadal climate, with common specification of AMIP radiative and ocean boundary conditions. To quantify this sensitivity, we computed spatio-temporal measures of intraensemble reproducibility, with particular attention to their values at the land surface. We considered the reproducibility of the surface variables when the seasonal cycle was included or excluded, since the former configuration is relevant for model intercomparison projects, and the latter for seasonal climate forecasts. Here we elaborate possible ramifications of our study for both these endeavors.

\section{a. Implications for model intercomparisons}

Because chaos complicates the analysis of a climate simulation, it is well to focus a model intercomparison project on variables that display low sensitivity to initial conditions. Our reproducibility measures indicate this to be the case for most land-surface variables that include the seasonal cycle, with the possible exception of precipitation and surface wind stresses. However, the 10year seasonal climatologies of even these highly chaotic variables proved to be spatially reproducible to a very great degree. This suggests that the comparison of seasonal land-surface climatologies across different atmospheric GCMs is likely to be a meaningful exercise, provided that common radiative and ocean boundary conditions are specified, such as in the AMIP experiments. (The intercomparison of models' monthly climatologies seems somewhat more problematical, however, in view of their greater sensitivity to initial conditions.) 
A more fundamental problem for intercomparison projects focussing on the effects of different coupled land-surface schemes is that simulations of continental climate reflect the biases of the atmospheric models' surface forcings (e.g. net radiation or precipitation), thus making it difficult to assess the degree to which the different embedded land-surface schemes influence the simulation. In principle, the effects of these biases could be reduced by intercomparing the models' land-surface anomalies (i.e. the departures from the respective seasonal cycles). However, our study shows this to be an inadequate general strategy for single realizations of each model's climate, given the highly chaotic behavior of these anomalies outside the deep Tropics.

Such an approach would only be effective if multiple realizations of seasonal land-surface climate were available for each model, so that the reproducible part of each anomaly could be estimated from its ensemble mean; however, many realizations probably would be needed for an accurate estimate of this type (Barnett 1995, Wehner 2000). Because such a computationally intensive model intercomparison project is still rather impractical, other methods for a posteriori reduction of the effects of model biases in single realizations need to be explored. For example, one potentially promising approach is to construct dimensionless ratios of response/forcing variables to elucidate essentially different behaviors of coupled land-surface schemes (Gedney et al. 2000).

\section{b. Implications for seasonal forecasting}

In this study we also inferred the potential predictability (PP) of the ECMWF model's landsurface climate by computing measures of the spatio-temporal reproducibility of the seasonal anomalies of like variables in the ensemble. There was a considerable range in the overall predictability of the model's land-surface processes, with continental surface pressure and temperature exhibiting generally higher PP than the hydrological variables or the turbulent fluxes; however, there were preliminary indications that the spatial pattern of the latter processes may be somewhat more predictable than that of the former. Surface pressure and temperature also manifested PP over the extratropical continents, albeit only in selected regions and seasons (see Figures 16 and 17). The overall PP of the model's seasonal continental climate was really substantial only in the deep Tropics, however. These results were consistent with those implied by more conventional predictability measures.

The PP of the simulated seasonal continental climate also was perceptibly enhanced during ENSO events, in particular the intense 1982/83 El Niño. However, the ENSO teleconnection was not as evident when the predictions of the ECMWF model were compared against an independent validation reference such as the NCEP-NCAR reanalysis data: in this context, the relationship of the ENSO to the model's continental climate seemed quite tenuous outside the Tropics. 
These rather sobering implications for the potential predictability of extratropical continental climate from SSTs alone need to be tempered by consideration of several means for enhancing seasonal forecast skill. First, in contrast to our experiments, operational seasonal predictions usually proceed from initial conditions specified from the observed atmospheric state (e.g. as provided by analysis products), so that some additional predictive skill may be imparted by atmospheric persistence, at least in the earlier stages of the seasonal forecast (e.g. Dirmeyer et al. 2001).

There is also considerable evidence (e.g. Huang et al. 1996, Wang and Kumar 1998, Cohen and Entekhabi 1998, Ferranti et al. 1999, Koster et al. 2000, Dirmeyer 2000) that seasonal predictive skill can be enhanced by accurate specification of other sources of climate memory such as snow cover and soil moisture (where the latter is treated as a predictor variable rather than a predictand, as in our study). Additional knowledge of the ocean state (other than provided by SSTs) also may yield an enhanced set of seasonal climate predictors (e.g. Phillips 1992, Griffies and Bryan 1997). Progress on these fronts no doubt will be closely tied to integrated remote sensing and modeling initiatives promoted by the World Climate Research Programme and similar international collaborations.

Seasonal predictions also may be enhanced by intelligent use of statistical forecasting techniques: because the land-surface variables are correlated, skillful dynamical forecasts of selected fields can impart statistical knowledge of others (Barnston and Smith 1996). Enhanced forecast skill may also be realized by reducing systematic model errors through statistical correction techniques (Smith and Livezey 1999, Feddersen et al. 1999), by combining dynamical and statistical forecasting techniques (Anderson et al. 1999), or by utilizing ensemble forecasts from more than one model (Mason et al. 1999).

Finally, we reiterate that the predictability of land-surface climate is partly a function of model performance (Kumar et al. 1996, Sperber and Palmer 1996, Liang et al. 1997, Zwiers and Kharin 1998, Sperber et al. 1999). Hence, with future advances in computer technology facilitating increasingly realistic simulations of continental processes, there is reason to anticipate substantial further progress in our ability to predict seasonal land-surface climate.

\section{Acknowledgments}

Special thanks are due to Ben Santer for recommending the reproducibility metrics used in this study. The cooperation of the ECMWF in making available their model also is gratefully acknowledged. This work was performed under the auspices of the U.S. Department of Energy by the University of California Lawrence Livermore National Laboratory under Contract No. W-7405-ENG-48. 


\section{References}

Anderson, J.L., and W.F. Stern, 1996: Evaluating the potential predictive utility of ensemble forecasts. J. Climate, 9, 260-269.

Anderson, J., H. van den Dool, A. Barnston, W. Chen, W. Stern, and J. Ploshay, 1999: Present-day capabilities of numerical and statistical models for atmospheric extratropical seasonal simulation and prediction. Bull. Amer. Meteor. Soc., 80, 1349-1361.

Barnett, T.P., 1995: Monte Carlo climate forecasting. J. Climate, 8, 1005-1022.

Barnett, T.P., 1988: Variations in near-global sea level pressure: Another view. J. Climate, 1, 225-230.

Barnston, A.G., 1994: Linear statistical short-term climate predictive skill in the Northern Hemisphere. J. Climate, 7, 1513-1564.

Barnston, A.G., and T.M. Smith, 1996: Specification and prediction of global surface temperatures and precipitation from global SST using CCA. J. Climate, 9, 2660-2697.

Beljaars, A.C.M., P. Viterbo, and M.J. Miller, 1996: The anomalous rainfall over the United States during July 1993: Sensitivity to land surface parameterization and soil moisture anomalies. Mon. Wea. Rev., 124, 362-383.

Bengtsson, L., and J. Shukla, 1988: Integration of space and in situ observations to study global climate change. Bull. Amer. Meteor. Soc., 69, 1130-1143.

Bengtsson, L., K. Arpe, E. Roeckner, U. Schulzweida, 1996: Climate predictability experiments with a general circulation model. Climate Dyn., 12, 261-278.

Betts, A.K., J.H. Ball, and A.C.M. Beljaars, 1993: Comparison between the land surface response of the ECMWF model and the FIFE-1987 data. Quart. J. Roy. Meteor. Soc., 119, 975-1001.

Blondin, C., 1989: Research on land surface parameterisation schemes at ECMWF. In Proceedings of the Workshop on Parameterisation of Fluxes over Land Surface, European Centre for Medium-Range Weather Forecasts, Reading, England.

Brankovic, C., T.N. Palmer, and L. Ferranti, 1994: Predictability of seasonal atmospheric variations. J. Climate, 7, 217-237.

Carson, D.J. 1998: Seasonal forecasting. Quart. J. Roy. Meteor. Soc., 124, 1-26.

Chen, W.Y., and H.M. van Van den Dool, 1997: Atmospheric predictability of seasonal, annual, and decadal climate means and the role of the ENSO cycle: A model study. J. Climate, 10, 1236-1254.

Chervin, R. M., 1986: Interannual variability and seasonal climate predictability. J. Atmos. Sci., 43, 233-251.

Cohen, J., and D. Entekhabi, 1998: Eurasian snow cover variability and Norther Hemisphere climate predictability. Geophys. Res. Letters, 26, 345-348. 
Cubasch, U., B.D. Santer, A. Helibach, G. Hegerl, H. Höck, E. Maier-Reimer, U. Mikolajewicz, A. Stoessel, and R. Voss, 1994: Monte Carlo climate change forecasts with a global coupled ocean-atmosphere model. Clim. Dynam., 10, 1-19.

Delworth, T.L., and T.R. Knutson, 2000: Simulations of early 20th century global warming. Science, 287 (5461), 2246-2250.

Dirmeyer, P.A., 2000: An evaluation of the strength of land-atmosphere coupling. COLA Tech. Rept. 89, Center for Ocean-Land-Atmosphere Studies, Calverton, Maryland, 30 pp.

Dirmeyer, P.A., M.J. Fennessy, and L. Marx, 2001: Near surface boreal summer climate as simulated by three general circulation models. COLA Technical Report \#100, Center for Ocean-Land-Atmosphere Studies, Calverton, Maryland 20705-3106, USA, 36 pp.

Dix, M.R., and B.G. Hunt, 1995: Chaotic influences and the problem of deterministic seasonal predictions. Int. J. Climatol., 15, 729-752.

Ebisuzaki, W., 1995: The potential predictability in a 14-year GCM simulation. J. Climate, 8, 2749-2761.

ECMWF Research Department, 1988: ECMWF forecast model, adiabatic part (2nd edition). European Centre for Medium-Range Weather Forecasts, Reading, England.

ECMWF Research Department, 1991: ECMWF forecast model, physical parameterisation (3rd edition). European Centre for Medium-Range Weather Forecasts, Reading, England.

Feddersen, H., A. Navarra, and M.N. Ward, 1999: Reduction of model systematic error by statistical correction for dynamical seasonal prediction. J. Climate, 12, 1974-1989.

Ferranti, L. J.M. Slingo, T.N. Palmer, and B.J. Hoskins, 1999: The effect of land-surface feedbacks on the monsoon circulation. Quar. J. Roy. Meteor. Soc., 125, 1527-1550.

Gates, W.L., 1992: AMIP: The Atmospheric Model Intercomparison Project. Bull. Amer. Meteor. Soc., 73, 1962-1970.

Gates, W.L., and Coathors, 1999: An overview of the results of the Atmospheric Model Intercomparison Project (AMIP I). Bull. Amer. Meteor. Soc., 80, 29-55.

Gedney, N., P.M. Cox, H. Douville, J. Polcher, and P.J. Valdes, 2000: Characterising GCM land surface schemes to understand their responses to climate change. J. Climate, 13, 3066-3079.

Griffies, S.M., and K. Bryan, 1997: A predictability study of simulated North Atlantic multidecadal variability. Climate Dyn., 13, 459-487.

Hansen, J., and coauthors, 1997: Forcings and chaos in interannual to decadal climate change. $J$. Geophys. Res., 102, 25679-25720.

Henderson-Sellers, A., K. McGuffie, and A.J. Pitman, 1996: The Project for Intercomparison of Land-Surface Parameterization Schemes: 1992 to 1995. Climate Dyn., 12, 849-859.

Higgins, W. and M. Halpert, 1997: Oceanic and atmospheric anomalies in the global Tropics: The 1997 El Niño. In the Proceedings of the Twenty-Second Annual Climate Diagnostics and Prediction Workshop, Berkeley, California, 6-10 October 1997, pp. 1-5. 
Hoerling, M.P., M. Ting, and A. Kumar, 1995: Zonal-flow stationary wave relationship during El Niño: Implications for seasonal forecasting. J. Climate, 8, 1838-1852.

Huang, J., H.M. van den Dool, and K.P. Georgakakos, 1996: Analysis of model-calculated soil moisture over the United States (1931-1993) and applications to long range temperature forecasts. J. Climate, 9, 1350-1362.

Kalnay, E. and coauthors, 1996: The NMC/NCAR 40-year reanalysis project. Bull. Amer. Meteor. Soc., 77, 437-471.

Kane, R.P., 1997: Relationship of El Niño-Southern Oscillation and Pacific sea surface temperature with rainfall in various regions of the globe. Mon. Wea. Rev., 125, 1792-1800.

Kiladis, G.N., and H.F. Diaz, 1989: Global climatic anomalies associated with extremes in the Southern Oscillation. J. Climate, 2, 1069-1090.

Koster, R.D., and M.J. Suarez, 1994: The components of a 'SVAT' scheme and their effects on a GCM's hydrological cycle. Adv. Water Res., 17, 61-78.

Koster, R.D., M.J. Suarez, and M Heiser, 2000: Variance and predictability of precipitation at seasonal-to-interannual timescales. J. Hydrometeor. , 1, 26-46.

Kumar, A., and M.P. Hoerling, 1995: Prospects and limitations of atmospheric GCM climate predictions. Bull. Amer. Meteor. Soc., 76, 335-345.

Kumar, A., M. Hoerling, M. Ji, A. Leetmaa, and P. Sardeshmukh, 1996: Assessing a GCM's suitability for making seasonal predictions. J. Climate, 9, 240-247.

Leith, C.E., 1973: The standard error of time-averaged estimates of climatic means. J. Appl. Meteor., 12, 1066-1069.

Liang, X-Z., K.R. Sperber, W-C. Wang, and A.N. Samel, 1997: Predictability of SST forced climate signals in two atmospheric general circulation models. Climate Dyn., 13, 391-415.

Livezey, R.E., and W.Y. Chen, 1983: Statistical field significance and its determination by Monte Carlo techniques. Mon. Wea. Rev., 111, 46-59.

Lorenz, E.N., 1964: The problem of deducing the climate from the governing equations. Tellus, 16, 1-11.

Louis, J.-F., 1979: A parametric model of vertical eddy fluxes in the atmosphere. Bound. Layer Meteor., 17, 187-202.

Madden, R., A., 1981: A quantitative approach to long-range prediction. J. Geophys. Res., 86, 9817-9825.

Mason, S.J., L. Goddard, N.E. Graham, E. Yulaeva, L. Sun, and P.A. Arkin, 1999: The IRI seasonal climate prediction system and the 1997/98 El Niño event. Bull. Amer. Meteor. Soc., 80, 1853-1873. 
Miller, M.J., T.N. Palmer, and R. Swinbank R, 1989: Parameterization and influence of subgridscale orography in general circulation and numerical weather prediction models. Meteor. Atmos. Phys., 40, 84-109

Miller, M.J., A.C.M. Beljaars, and T.N. Palmer, 1992: The sensitivity of the ECMWF model to the parameterization of evaporation from the tropical oceans. J. Climate, 5, 418-434.

Morcrette, J-J. , 1991: Radiation and cloud radiative properties in the ECMWF operational weather forecast model. J. Geophys. Res., 96, 9121-9132.

Palmer, T.N., and D.L.T. Anderson, 1994: The prospects for seasonal forcasting--A review paper. Quart. J. Roy. Meteor. Soc., 120, 755-792.

Pan, H.-L., and W-S. Wu, 1994: Implementing a mass flux convective parameterization package for the NMC medium-range forecast model. Preprints, 10th Conf. on Numerical Weather Prediction, Portland, OR, Amer. Meteor. Soc., 96-98.

Phillips, T.J., 1992: An application of a simple coupled ocean-atmosphere model to the study of seasonal climate prediction. J. Climate, 5, 1078-1096.

Phillips, T.J., 1994: A summary documentation of the AMIP models. PCMDI Report No. 18, Program for Climate Model Diagnosis and Intercomparison, Lawrence Livermore National Laboratory, Livermore, CA, 346 pp. Also accessible online at http://www-pcmdi.llnl.gov/ modeldoc/amip1/ .

Phillips, T.J., A. Henderson-Sellers, P. Irannejad, K. McGuffie, H. Zhang, and the AMIP I Modeling Groups, 2000: Validation of land-surface processes in AMIP models: A pilot study. PCMDI Report No. 63, Program for Climate Model Diagnosis and Intercomparison, Lawrence Livermore National Laboratory, Livermore, CA, 20 pp. Also accessible online at http://www-pcmdi.llnl.gov/pcmdi/pubs/pdf/63.pdf .

Polcher, J. (ed.), 2000: Proceedings of the GEWEX/INSU International Workshop on Modelling Land-surface Atmosphere Interactions and Climate Variability, 4-8 October 1999, Gif-surYvette, France, 134 pp.

Quiroz, R.S., 1983: The climate of the "El Niño" winter of 1982-83--A season of extraordinary climatic anomalies. Mon. Wea. Rev., 111, 1685-1706.

Ropelewski, C.F., and M.S. Halpert, 1987: Global and regional scale precipitation patterns associated with the El Niño/Southern Oscillation. Mon. Wea. Rev., 115, 1606-1626.

Santer, B.D., 1988: Regional validation of general circulation models. Clim. Res. Unit Publ., 9, 375 pp. Univ. of East Anglia, Norwich, England.

Scott, R., D. Entekhabi, R. Koster, and M. Suarez, 1997: Timescales of landsurface evapotranspiration response. J. Climate, 10, 559-566.

Shukla, J., J. Anderson, D. Baumhefner, C. Brankovic, Y. Chang, E. Kalnay, L. Marx, T. Palmer, D. Paolino, J. Ploshay, S. Schubert, D. Straus, M. Suarez, and J. Tribbia, 2000: Dynamical seasonal prediction. Bull. Amer. Meteor. Soc., 81, 2593-2606. 
Slingo, J., 1987: The development and verification of a cloud prediction model for the ECMWF model. Quart. J. Roy. Meteor. Soc., 113, 899-927.

Smith, T.M., and R.E. Livezey, 1999: GCM systematic error correction and specification of the seasonal mean Pacific-North America region atmosphere from global SSTs. J. Climate, 12, 273-305.

Sperber, K.R., and T.N. Palmer, 1996: Interannual Tropical rainfall variability in general circulation model simulations associated with the Atmospheric Model Intercomparison Project. J. Climate, 9, 2727-2750.

Sperber, K.R., and Participating AMIP Modelling Groups, 1999: Are revised models better models? A skill score assessment of regional interannual variability. Geophys. Res. Letters, 26, 1267-1270.

Stern, W., and K. Miyakoda, 1995: The feasibility of seasonal forecasts inferred from multiple GCM simulations. J. Climate, 8, 1071-1085.

Sud, Y.C., G.K. Walker, and K.-M. Lau, 1999: Mechanisms regulating sea-surface temperatures and deep convection in the Tropics. Geophys. Res. Letters, 26, 1019-1022.

Tiedtke, M., 1989: A comprehensive mass flux scheme for cumulus parameterization in large-scale models. Mon. Wea. Rev., 117,1779-1800

Viterbo, P., and A.C.M. Beljaars, 1995: An improved land surface parameterization scheme in the ECMWF model and its validation. J. Climate, 8, 2716-2748.

Wang, W., and A. Kumar, 1998: A GCM assessment of atmospheric seasonal predictability associated with soil moisture anomalies over North America. J. Geophys. Res., 103, 28,63728,646 .

Wang, X.L, and F.W. Zwiers, 1999: Interannual variability of precipitation in an ensemble of AMIP climate simulations conducted with the CCC GCM2. J. Climate, 12, 1322-1335.

Wehner, M.F., 2000: Determination of the sampling size of AGCM ensemble simulations. Climate Dyn., 16, 321-331.

Yang, Z.-L., R.E. Dickinson, A. Henderson-Sellers, and A.J. Pitman, 1995: Preliminary study of spin-up processes in land-surface models with the first stage data of PILPS Phase 1(a). $J$. Geophys. Res., 100, 16553-16578.

Zwiers, F.W., 1987: A potential predictability study conducted with an atmospheric general circulation model. Mon. Wea. Rev., 115, 2957-2974.

Zwiers, F.W., 1996: Interannual variability and predictability in an ensemble of AMIP climate simulations conducted with the CCC GCM2. Climate Dyn., 12, 825-847.

Zwiers, F.W., and V. Kharin, 1998: Intercomparison of interannual variability and potential predictability: an AMIP diagnostic subproject. Climate Dyn., 14, 417-528. 
Table 1: Surface variables considered in this study, listed in alphabetical order of their AMIP acronym, with units.

\begin{tabular}{|l|c|c|}
\hline Surface Variable & AMIP Acronym & Units \\
\hline \hline Evaporation & evs & $\mathrm{mm} \mathrm{day}^{-1}$ \\
\hline Sensible Heat Flux & hfss & $\mathrm{W} \mathrm{m}^{-2}$ \\
\hline Soil Moisture & mrso & $\mathrm{cm}$ \\
\hline Precipitation & pr & $\mathrm{mm} \mathrm{day}^{-1}$ \\
\hline Sea-level Pressure & psl & $\mathrm{hPa}^{-2}$ \\
\hline Net Longwave Radiation & rls & $\mathrm{W} \mathrm{m} \mathrm{m}^{-2}$ \\
\hline Net Shortwave Radiation & rss & $\mathrm{deg} \mathrm{C}^{-2}$ \\
\hline Surface Air Temperature* & tas & $\mathrm{Nt} \mathrm{m}^{-2}$ \\
\hline Eastward Wind Stress & tauu & $\mathrm{Nt} \mathrm{m}^{-2}$ \\
\hline Northward Wind Stress & tauv & $\mathrm{deg} \mathrm{C}^{*}$ \\
\hline Ground Temperature* & tg & \\
\hline
\end{tabular}

$*$ Temperature of the lowest vertical level of the model atmosphere at $\sigma=0.996$, equivalent to a height $\sim 30$ meters above the surface.

** Equivalent to the surface skin temperature. 
a)

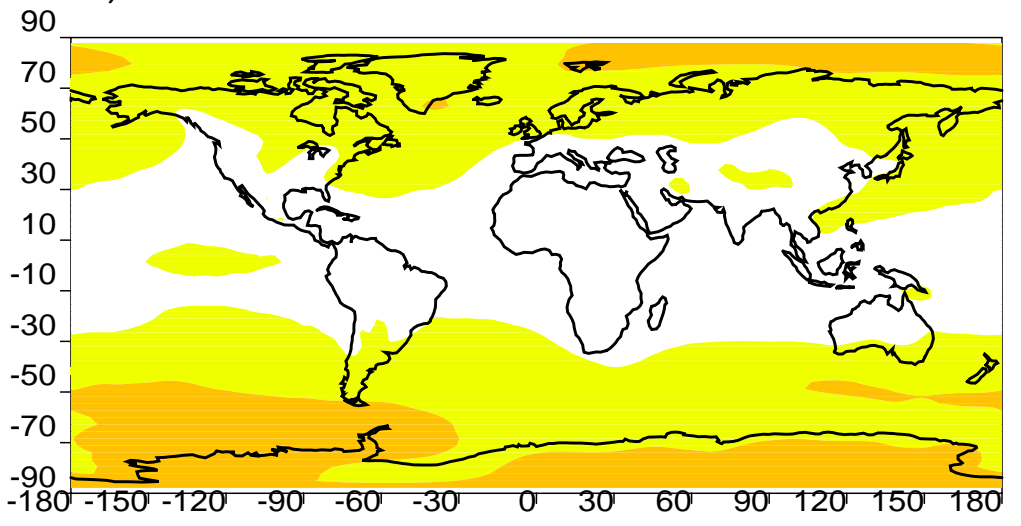

0

10

40

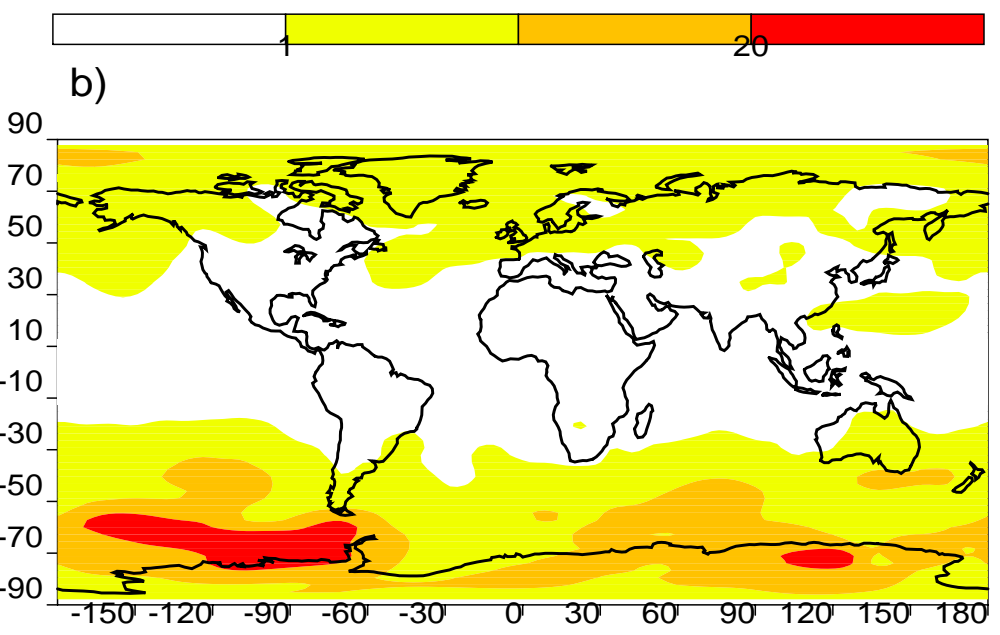

c)

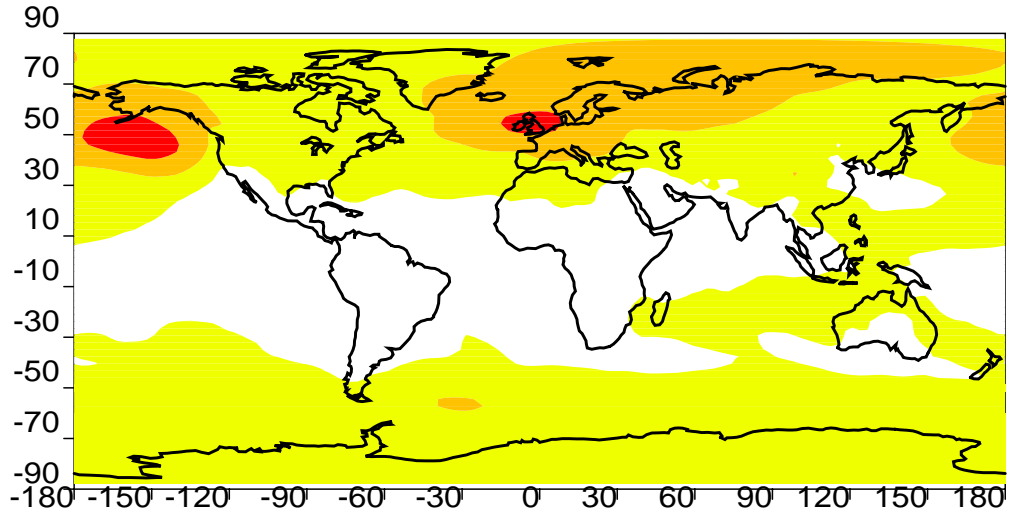

0

10

50

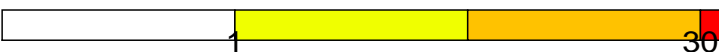

d)

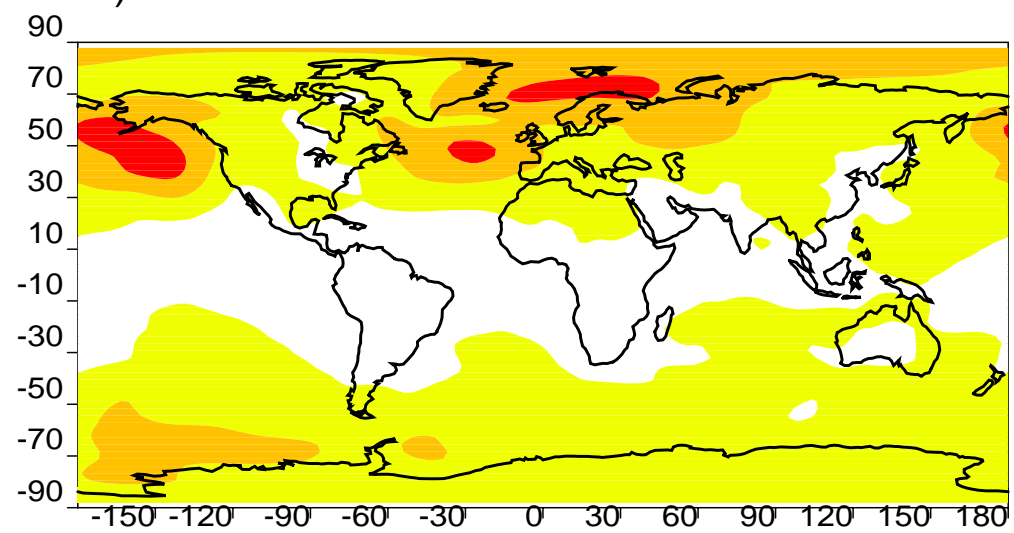

Figure 1: Maps of the interannual variance of JJA mean sea-level pressure, a) as simulated by the ECMWF (cycle 36) model and b) as obtained from NCEP-NCAR reanalysis data; and maps of the interannual variance of DJF mean sea-level pressure, c) as simulated, and d) as obtained from the reanalysis data. Units are (hPa) ${ }^{2}$. Note, the variances in a) and c) are calculated over 6 simulated realizations of the seasonal climates of 1979-1988, while those in b) and d) are calculated from the single available realization of the reanalysis climate over the same period. 
a)

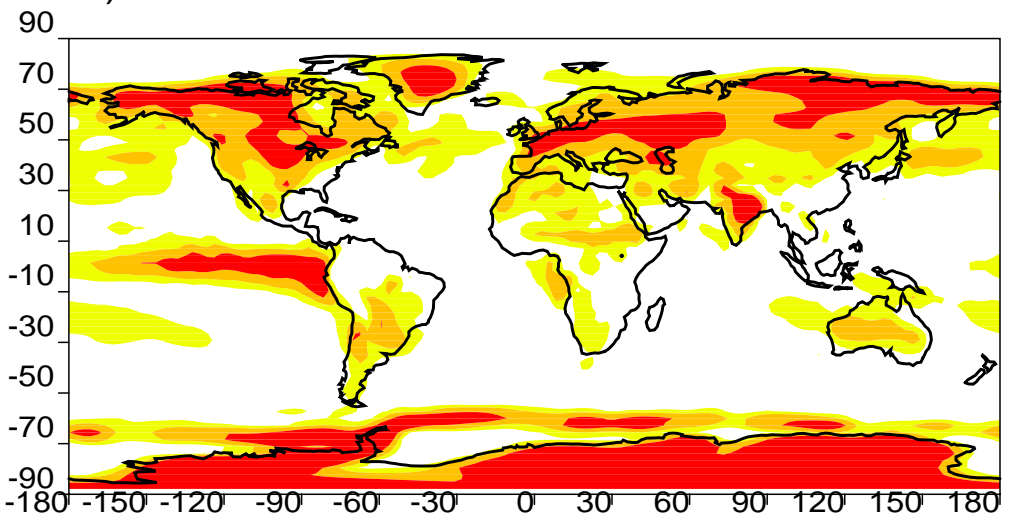

0

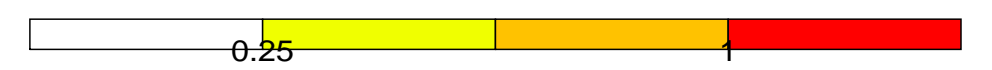

b)

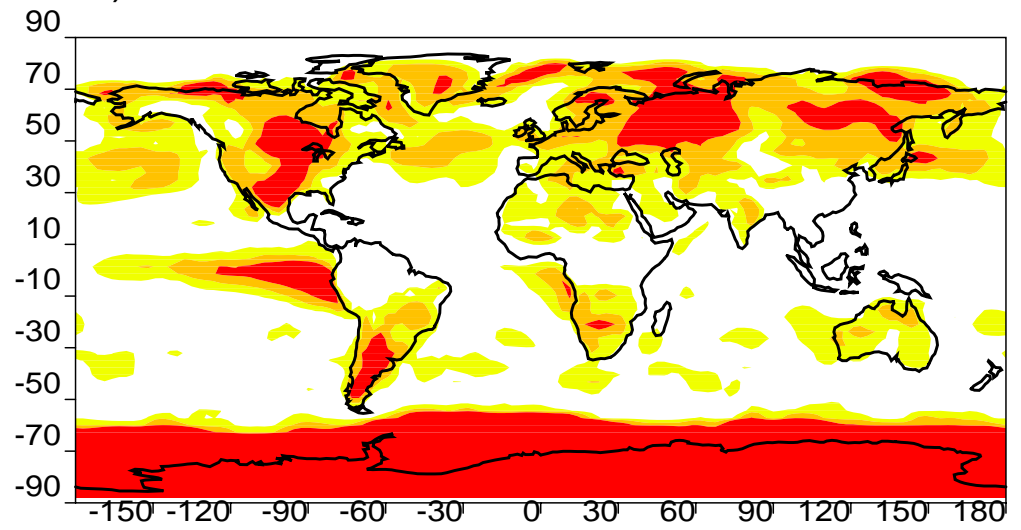

c)

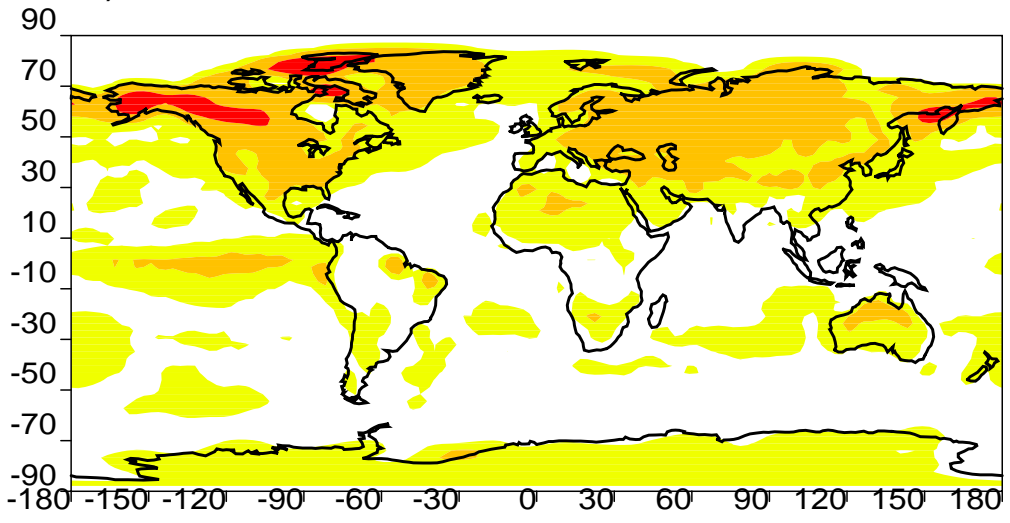

0

1

d)

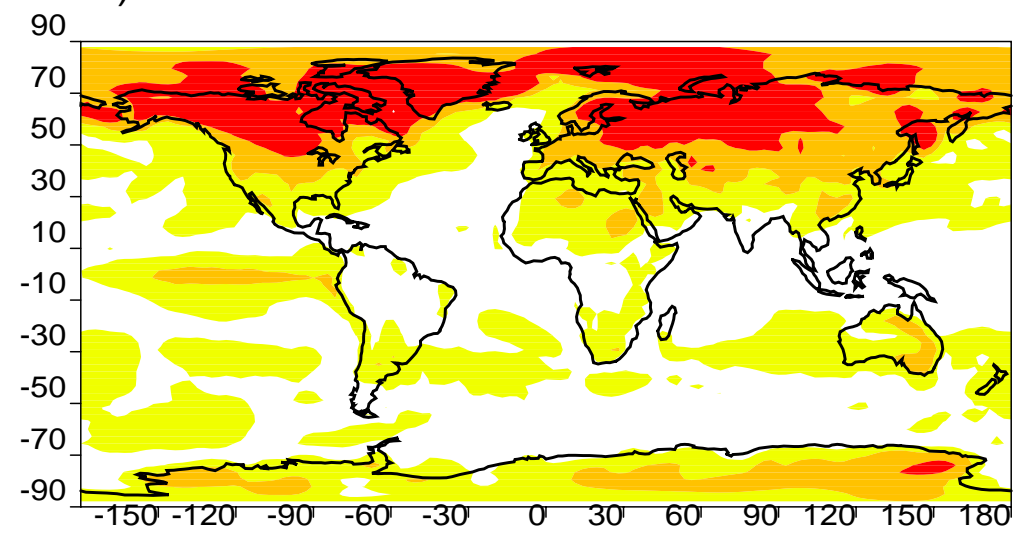

Figure 2: As in Figure 1, except for surface air temperature. Units are $(\operatorname{deg} C)^{2}$. 
a)

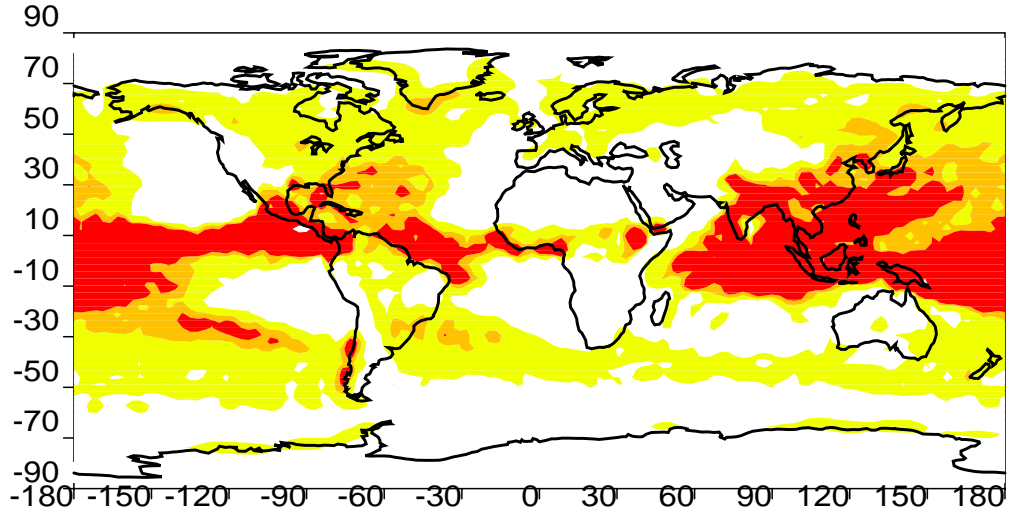$$
0
$$

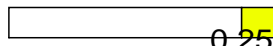

b)

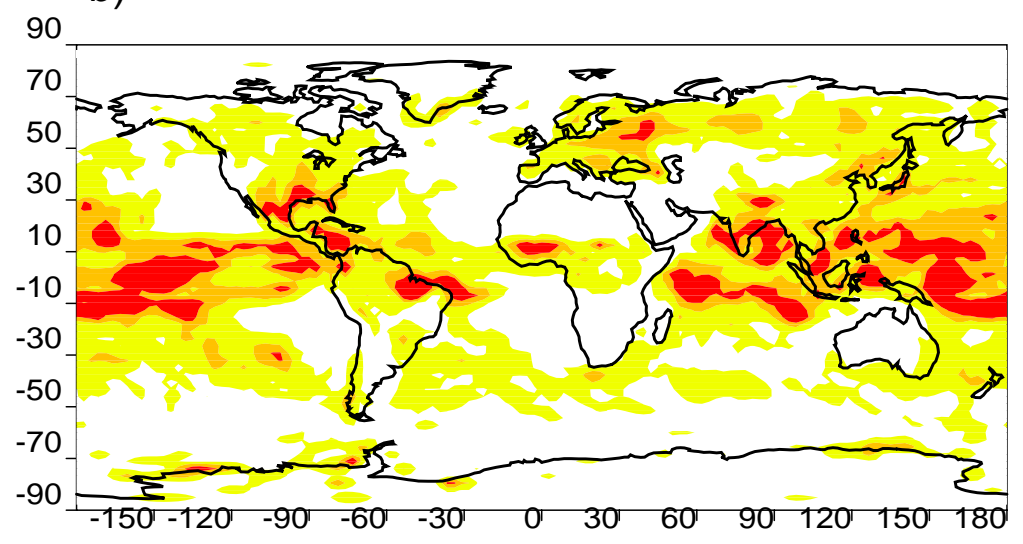

C)

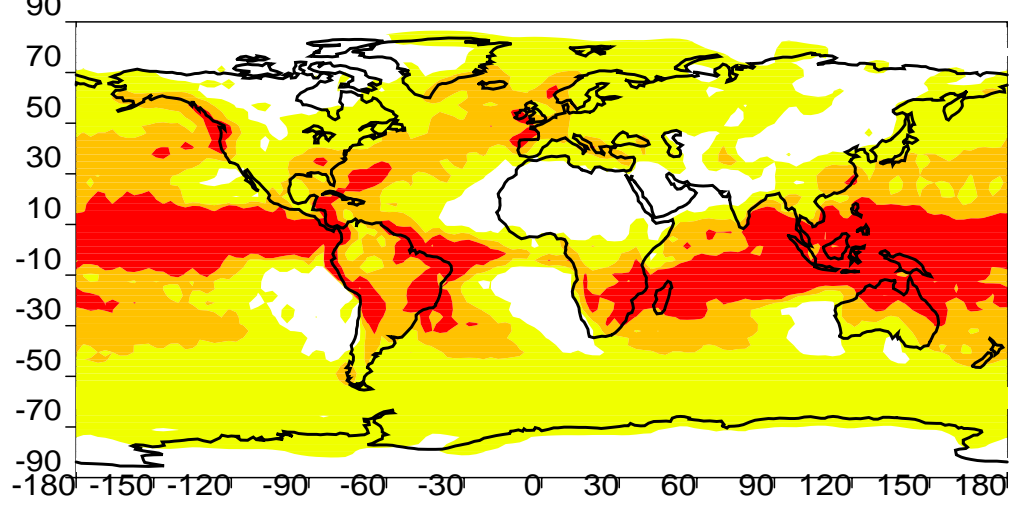

0

0.5

40

d)

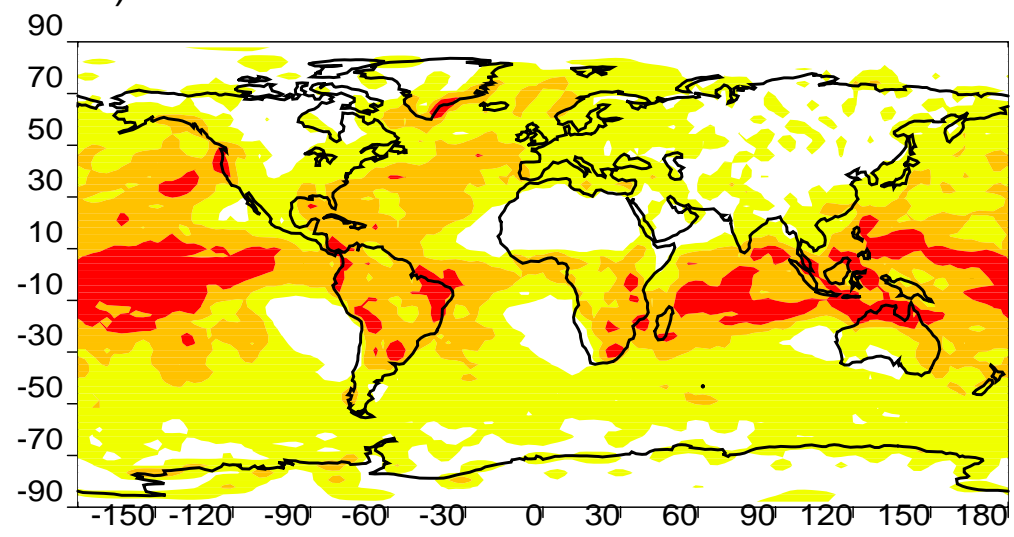

Figure 3: As in Figure 1, except for precipitation. Units are $\left(\mathrm{mm} \mathrm{day}^{-1}\right)^{2}$ 
a)

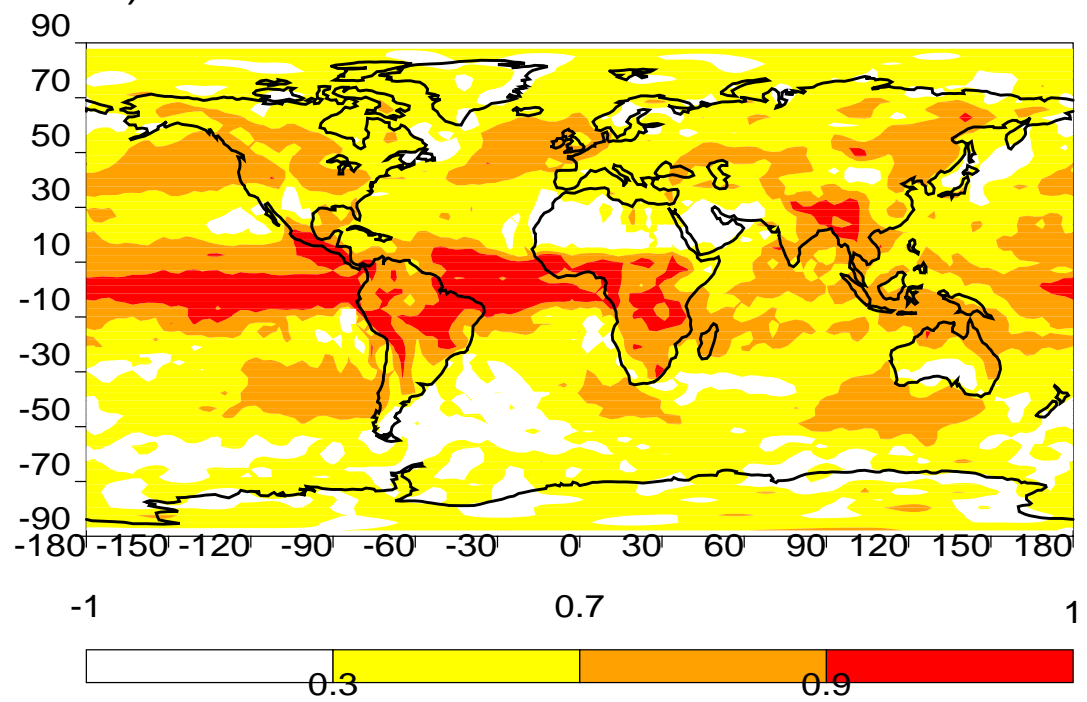

b)

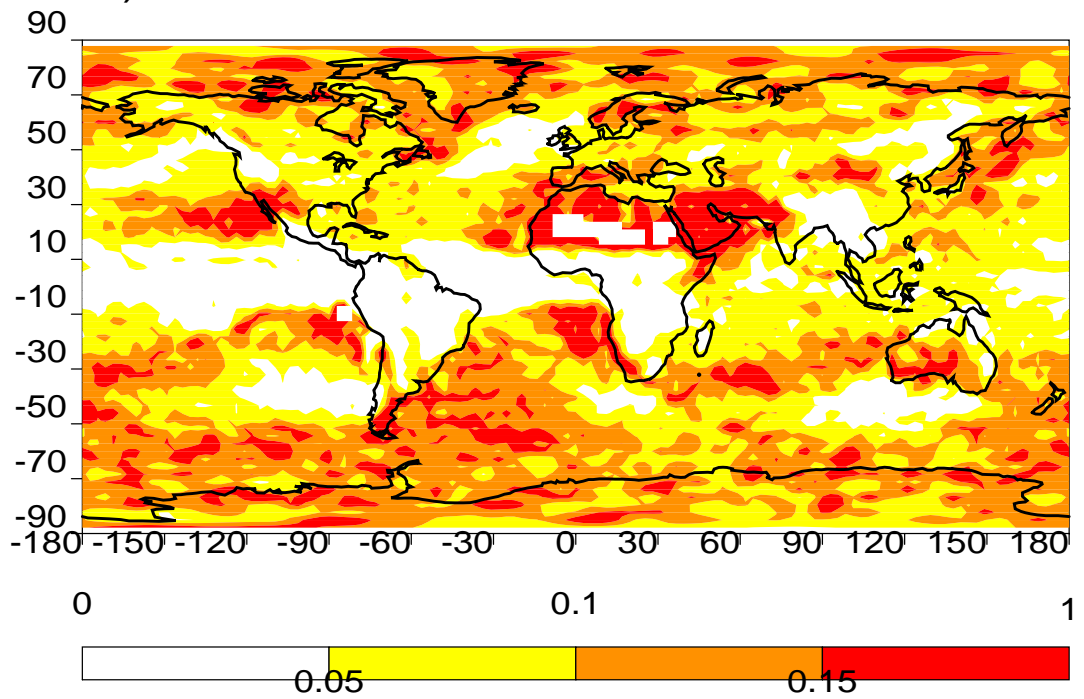

Figure 4: Maps of a) the mean $\mu[\mathbf{r}(i, j)]$ of zero-lag temporal cross-correlations $\mathbf{r}(\mathrm{i}, \mathrm{j})$ for seasonal precipitation as simulated for the AMIP decade by the ECMWF (cycle 36) model, and b) the associated cross-correlation scatter $\delta[\mathbf{r}(\mathrm{i}, \mathrm{j})]$. The statistics $\mu$ and $\delta$ are determined from $\mathrm{N}=15$ independent pairings of decadal seasonal realizations with the seasonal cycle included. 
a)

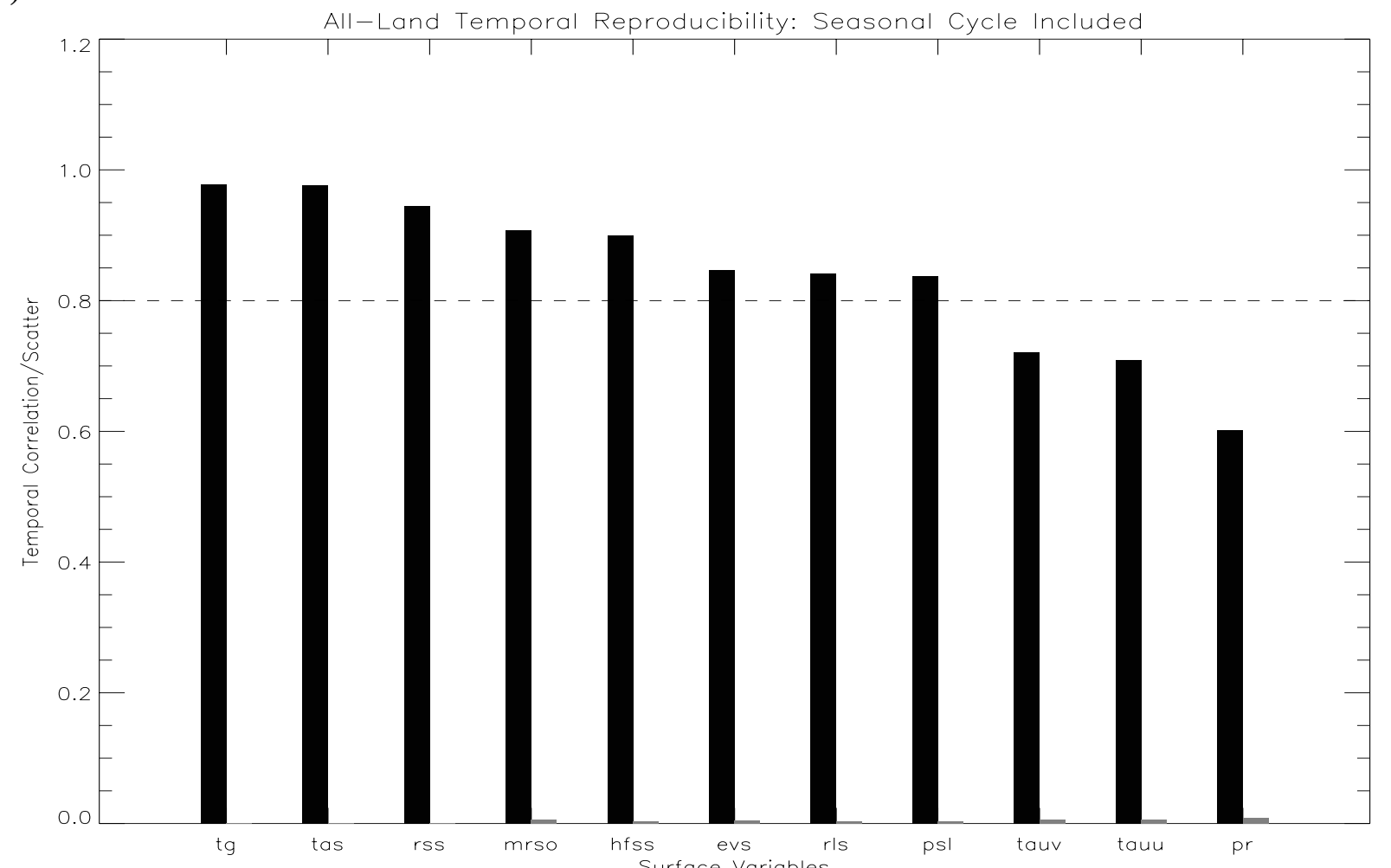

b)

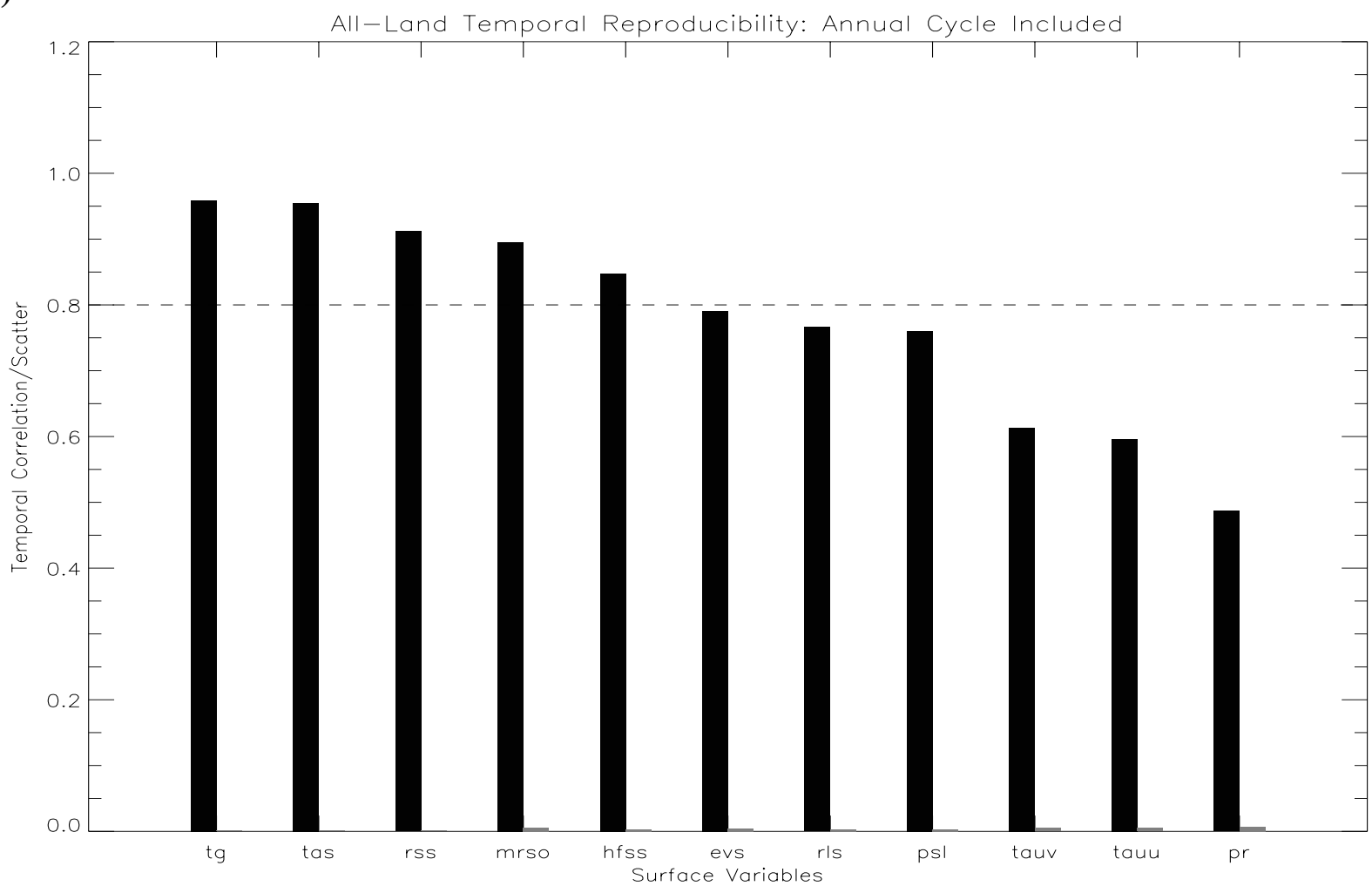

Figure 5: The mean $\mu\{\mathbf{R}\}$ (dark bars) and scatter $\delta\{\mathbf{R}\}$ (low-valued gray bars) of temporal correlations $\mathbf{R}$ over all land points are shown for 11 ECMWF model surface variables (see Table 1 for acronym definitions), where in a) the variables include the seasonal cycle (i.e. time series of MAM, JJA, SON, and DJF means), while those in b) include the annual cycle of monthly means. In both cases, the $\mathbf{R}$ statistics are computed from $\mathrm{N}=15$ independent realizations of the temporal cross-correlations $\mathbf{r}(\mathrm{i}, \mathrm{j})$, and the surface variables are arrayed from left to right in descending order of their $\mu\{\mathbf{R}\}$ values. As arbitrary common references in a) and b), the dashed horizontal lines indicate correlation/scatter values of 0.8 . 
a)
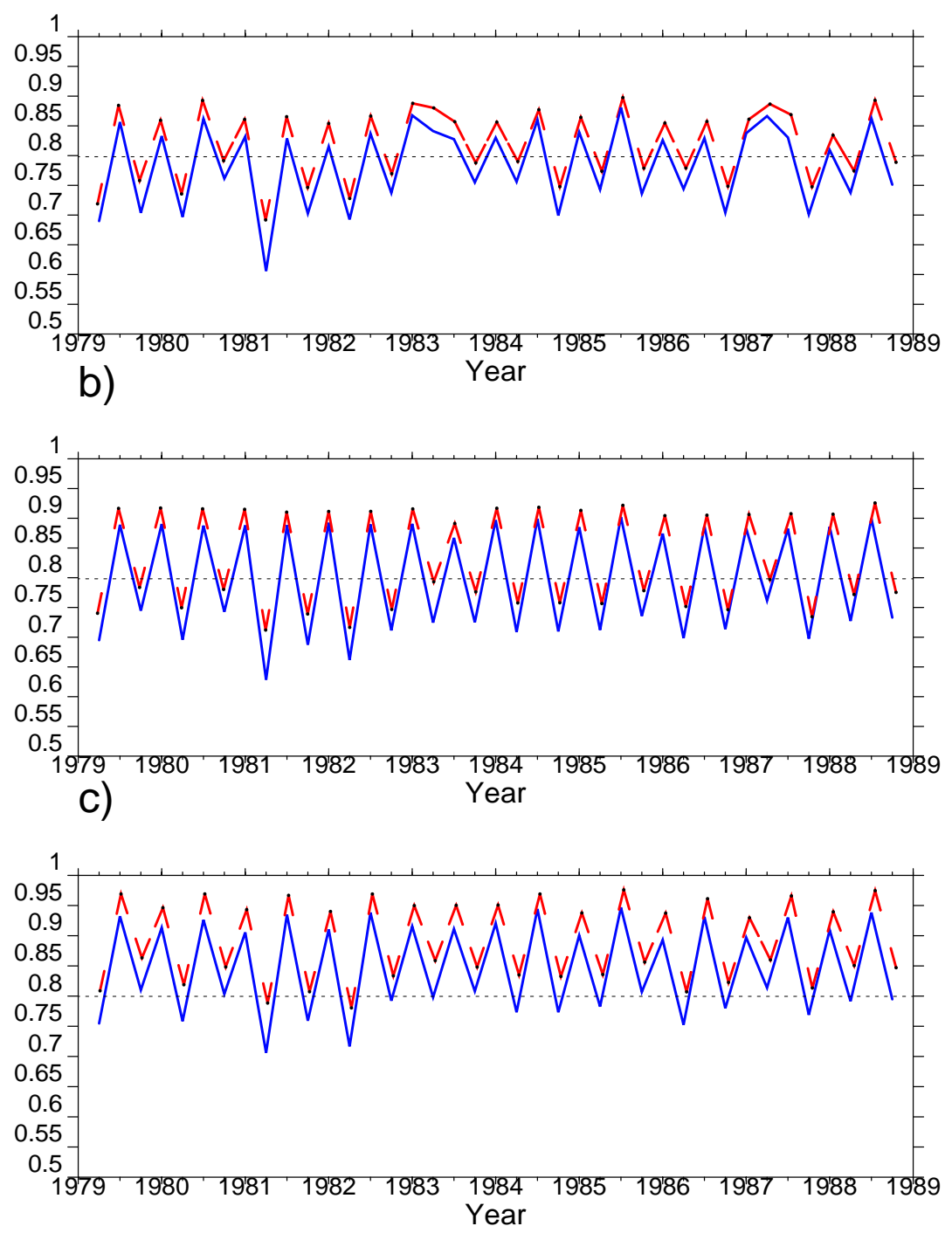

Figure 6: Time series of the mean $\mu[\mathrm{s}(\mathrm{k})]$ of spatial pattern cross-correlations for seasonal precipitation as simulated for the AMIP decade by the ECMWF (cycle 36) model (solid lines) and the associated cross-correlation scatter $\delta[\mathbf{s}(\mathrm{k})]$ (dashed lines). The statistics $\mu$ and $\delta$ are determined from $\mathrm{N}=15$ independent pairings of decadal seasonal realizations with the seasonal cycle included. The time series includes 39 seasonal samples $\mathrm{k}$, the first for the MAM 1979 season, and the last for the SON 1988 season. As arbitrary common references, the dashed horizontal lines indicate spatial pattern correlation values of 0.8. In a) the pattern correlations are computed globally, in b) they are computed over land points only, and in c) over tropical land points only ( $30 \mathrm{~S}$ to $30 \mathrm{~N})$. 


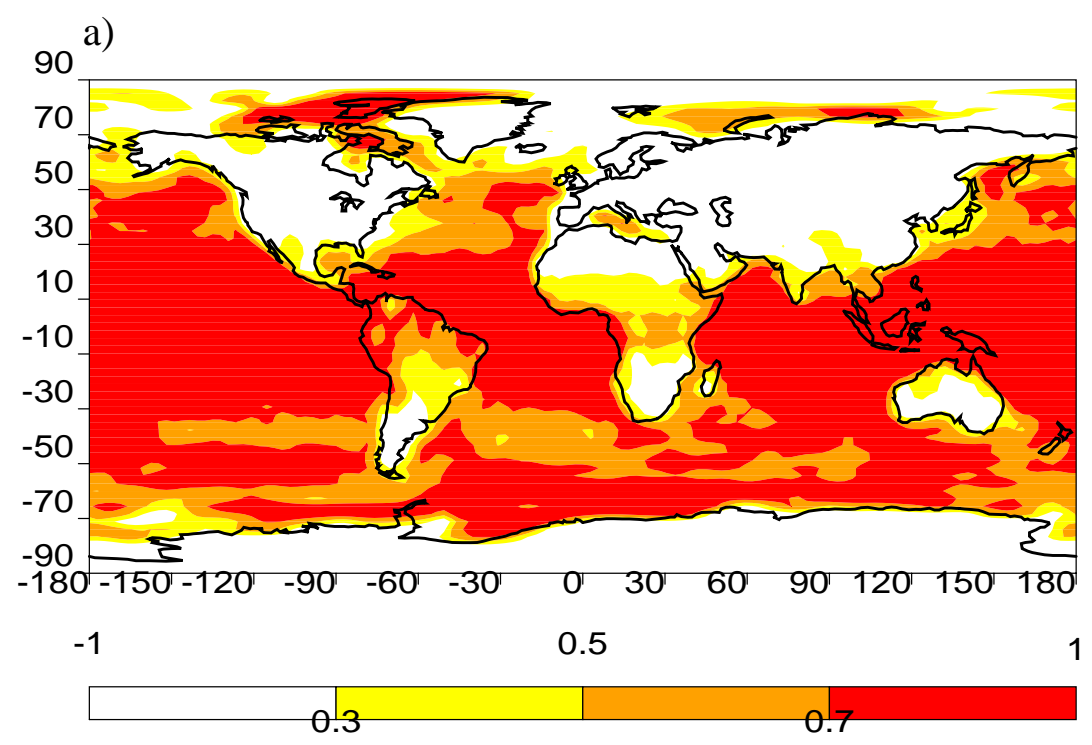

$$
90 \text { b) }
$$

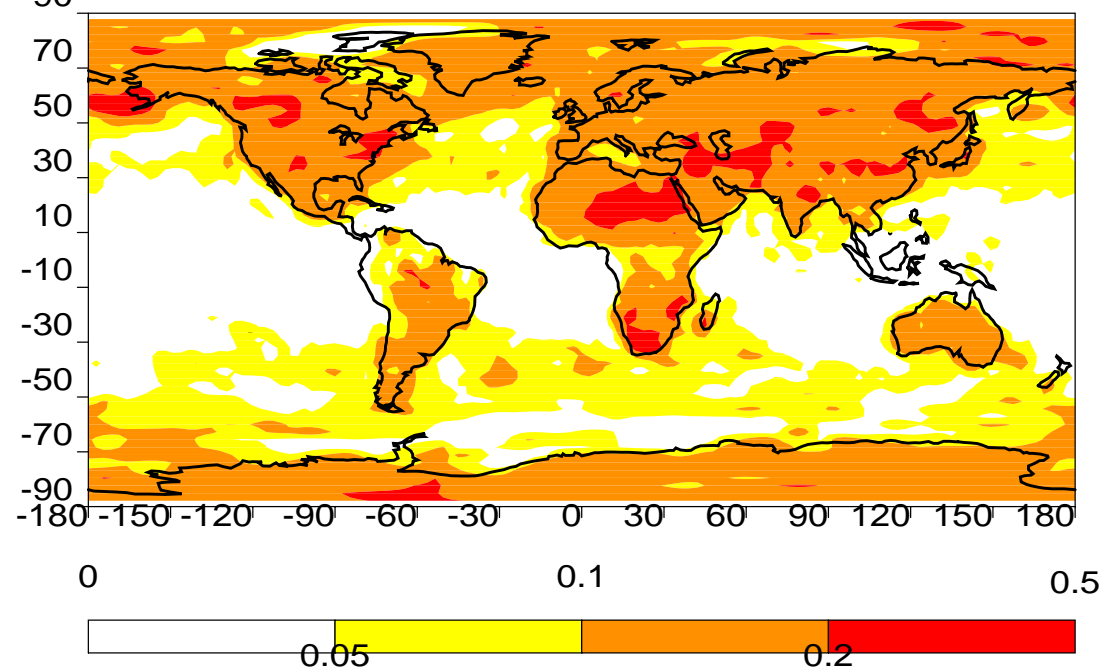

Figure 7: Map a) of the mean $\mu[\mathbf{r}(i, j)]$ of zero-lag temporal cross-correlations $\mathbf{r}(\mathrm{i}, \mathrm{j})$ for seasonal anomalies (i.e. excluding the seasonal cycle) of surface air temperature, as simulated for the AMIP decade by the ECMWF (cycle 36) model, and map b) of the associated intraensemble scatter $\delta[\mathbf{r}(\mathrm{i}, \mathrm{j})]$. The statistics $\mu$ and $\delta$ are determined from $\mathrm{N}=15$ independent crosscorrelations of decadal realizations of these anomalies. 
a)

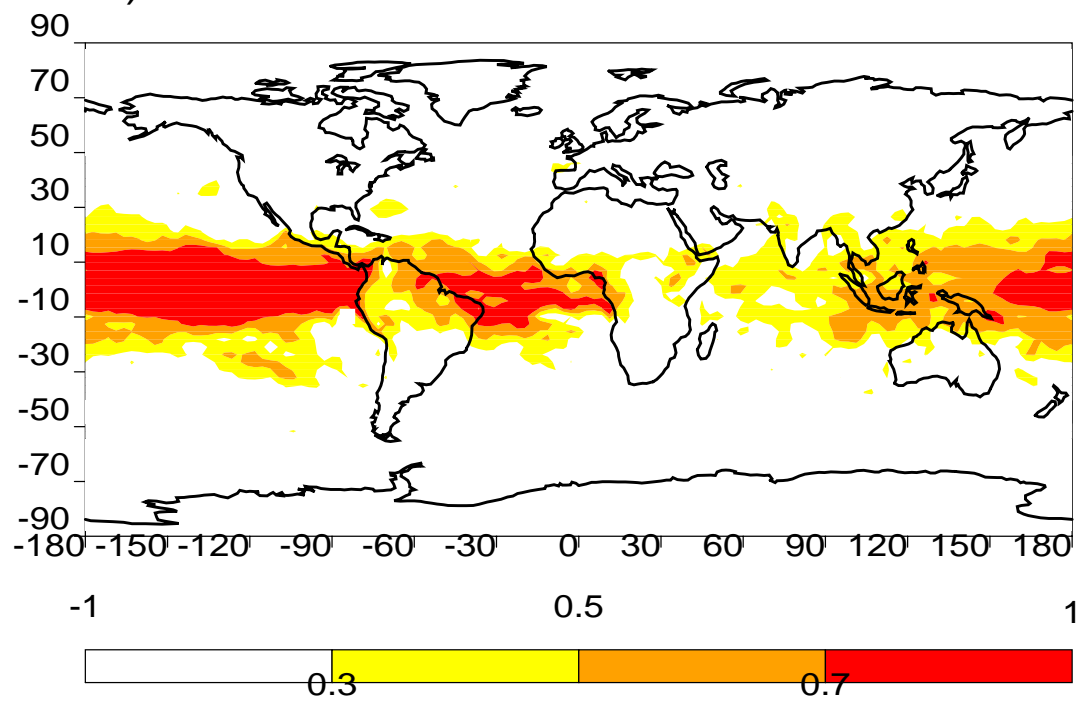

b)

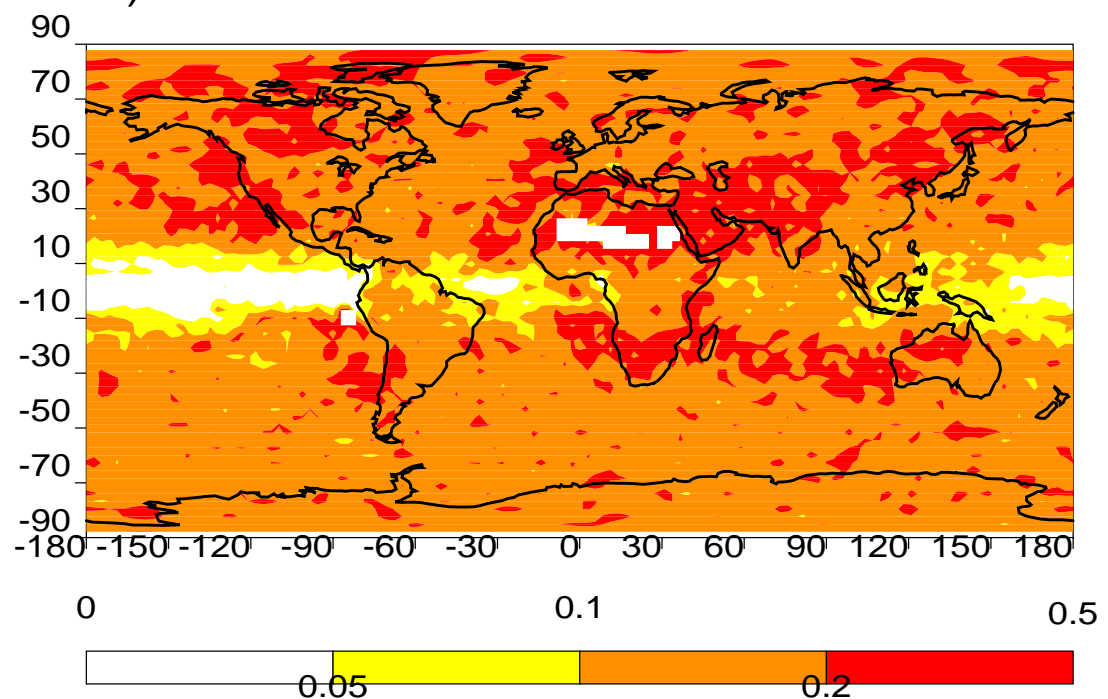

Figure 8: As in Figure 7, except for seasonal anomalies of precipitation. 
a)



b)

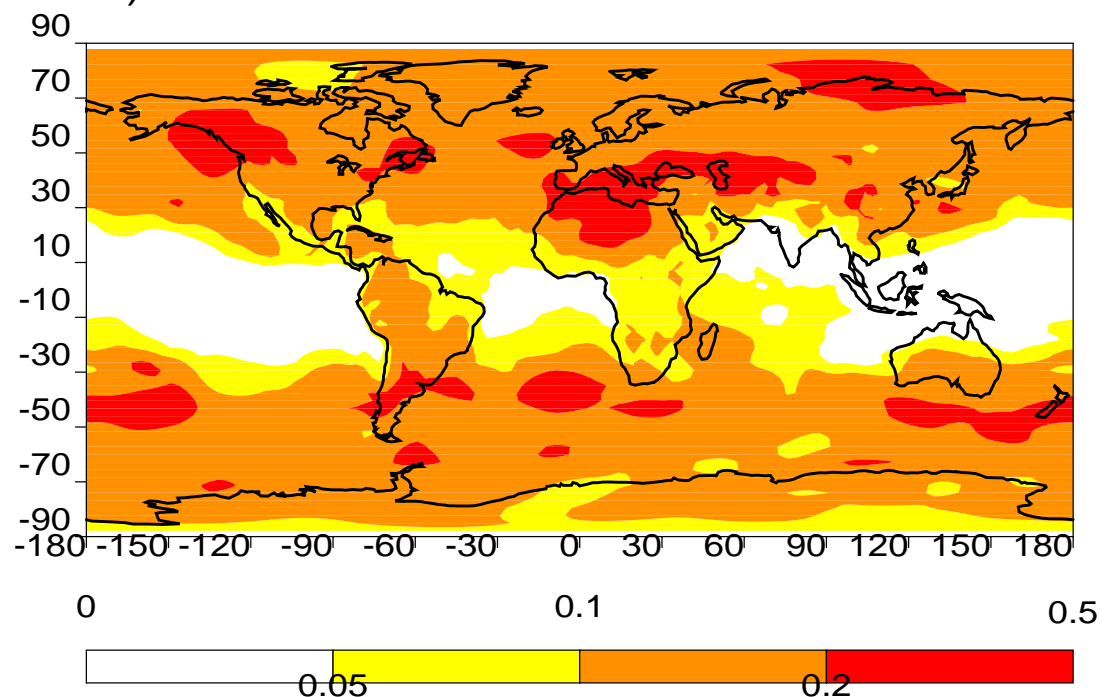

Figure 9: As in Figure 7, except for seasonal anomalies of mean sea-level pressure. 
a)

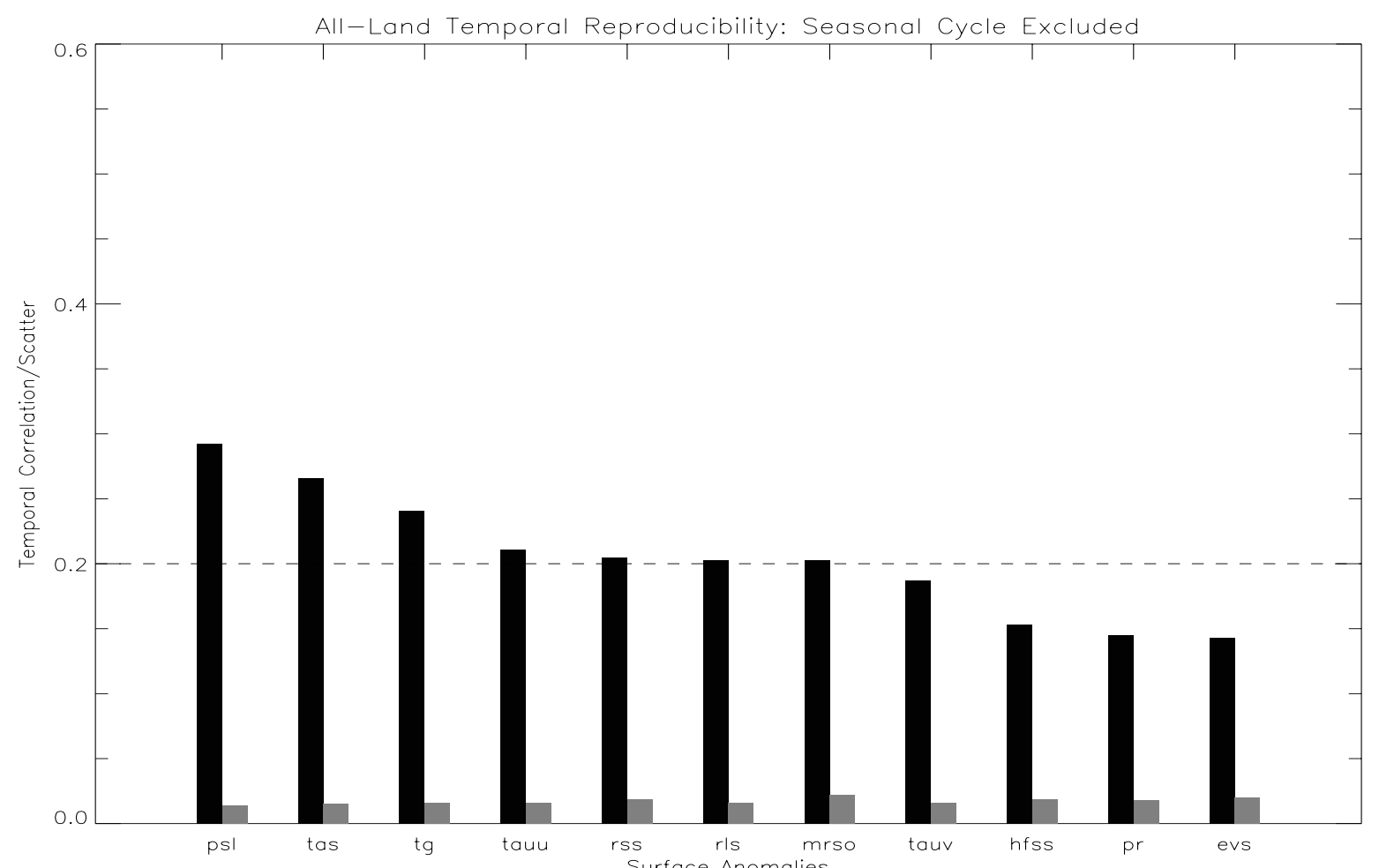

b)

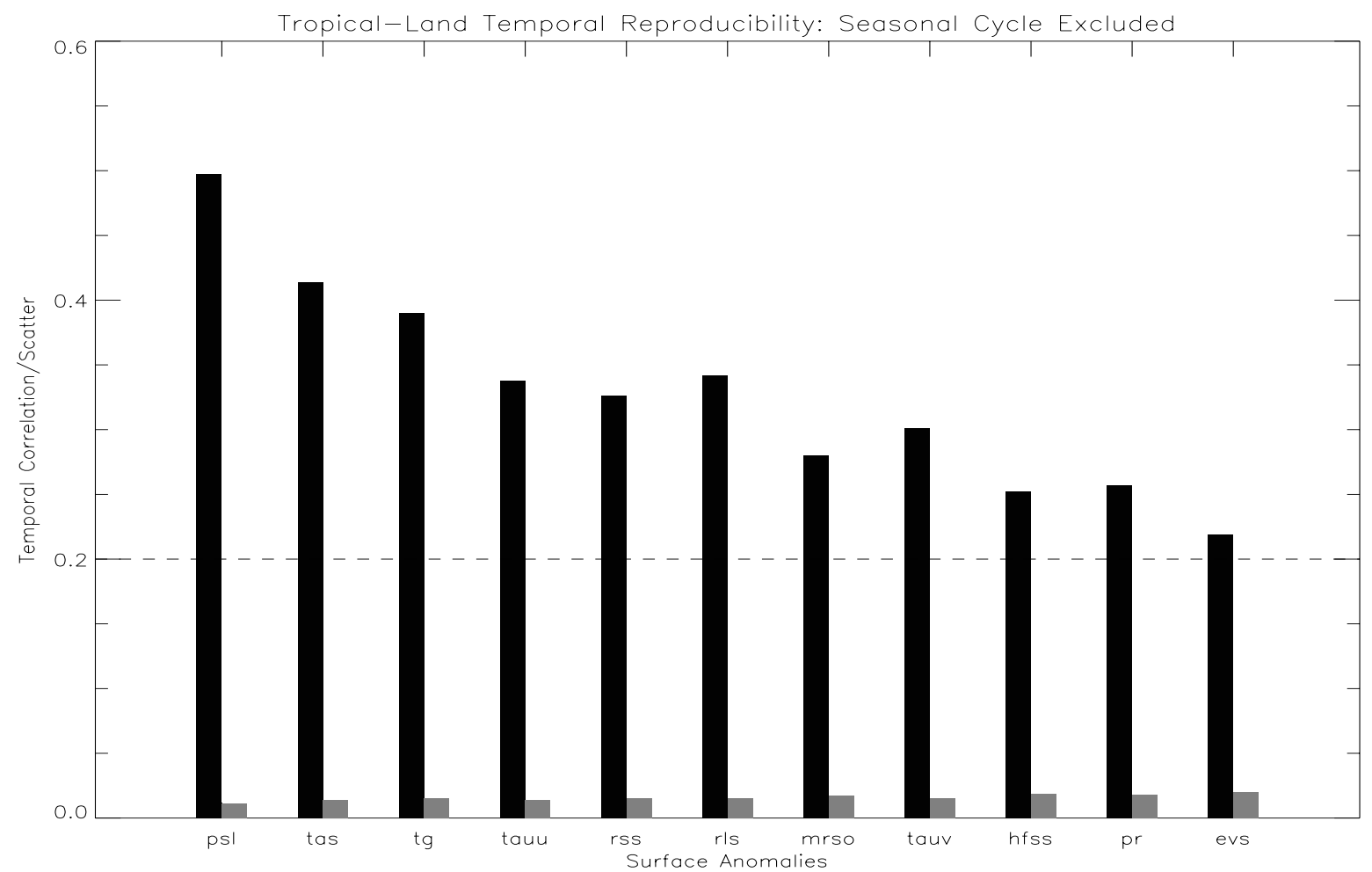

Figure 10: The mean $\mu\{\mathbf{R}\}$ (dark bars) and scatter $\delta\{\mathbf{R}\}$ (gray bars) of land-average temporal cross-correlations $\mathbf{R}$ for 11 seasonally averaged ECMWF model surface anomalies (see Table 1 for acronym definitions) are shown, in a) for correlations over all land points, and in b) for correlations only over tropical ( $30 \mathrm{~S}$ to $30 \mathrm{~N}$ ) land points. In both cases, the $\mathbf{R}$ statistics are computed from $\mathrm{N}=15$ independent realizations of the temporal cross-correlations $\mathbf{r}(\mathrm{i}, \mathrm{j})$, and the surface anomalies are arrayed from left to right in descending order of their all-land $\mu\{\mathbf{R}\}$ values. As arbitrary common references in a) and b), the dashed horizontal lines indicate mean correlation/scatter values of 0.2 . 
a)
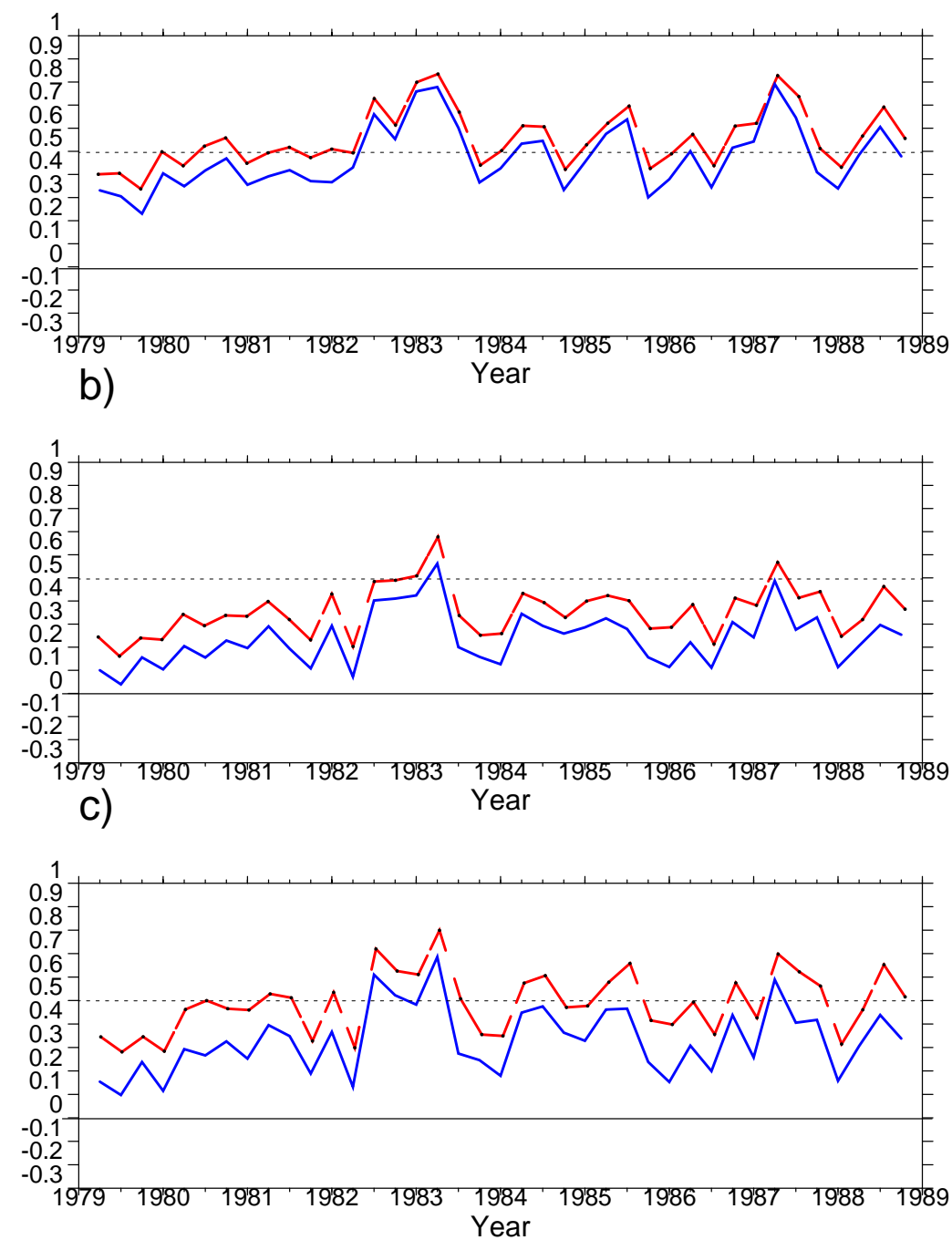

Figure 11: Time series of the mean $\mu\{\mathbf{s}(\mathrm{k})\}$ of spatial pattern cross-correlations $\mathbf{s}(\mathrm{k})$ for seasonal anomalies of precipitation (in blue), and the associated scatter $\delta\{\mathbf{s}(\mathrm{k})\}$ (in red), as simulated for the AMIP decade by the ECMWF (cycle 36) model. The time series comprises 39 seasonal samples k, the first at MAM of 1979 and the last at SON of 1988. (The MAM points are situated just to the right of the major tick marks labeled by each year on the abscissa.) As arbitrary common references, the dashed horizontal lines indicate correlation/scatter values of 0.5 . In a), the pattern correlations are computed globally (both land and ocean points), in b) only over land points, and in c) only over tropical $(30 \mathrm{~S}$ to $30 \mathrm{~N}$ ) land points. In all cases, the statistics are computed from $\mathrm{N}=15$ independent realizations of the spatial pattern correlations $\mathbf{s}(\mathrm{k})$. 
a)
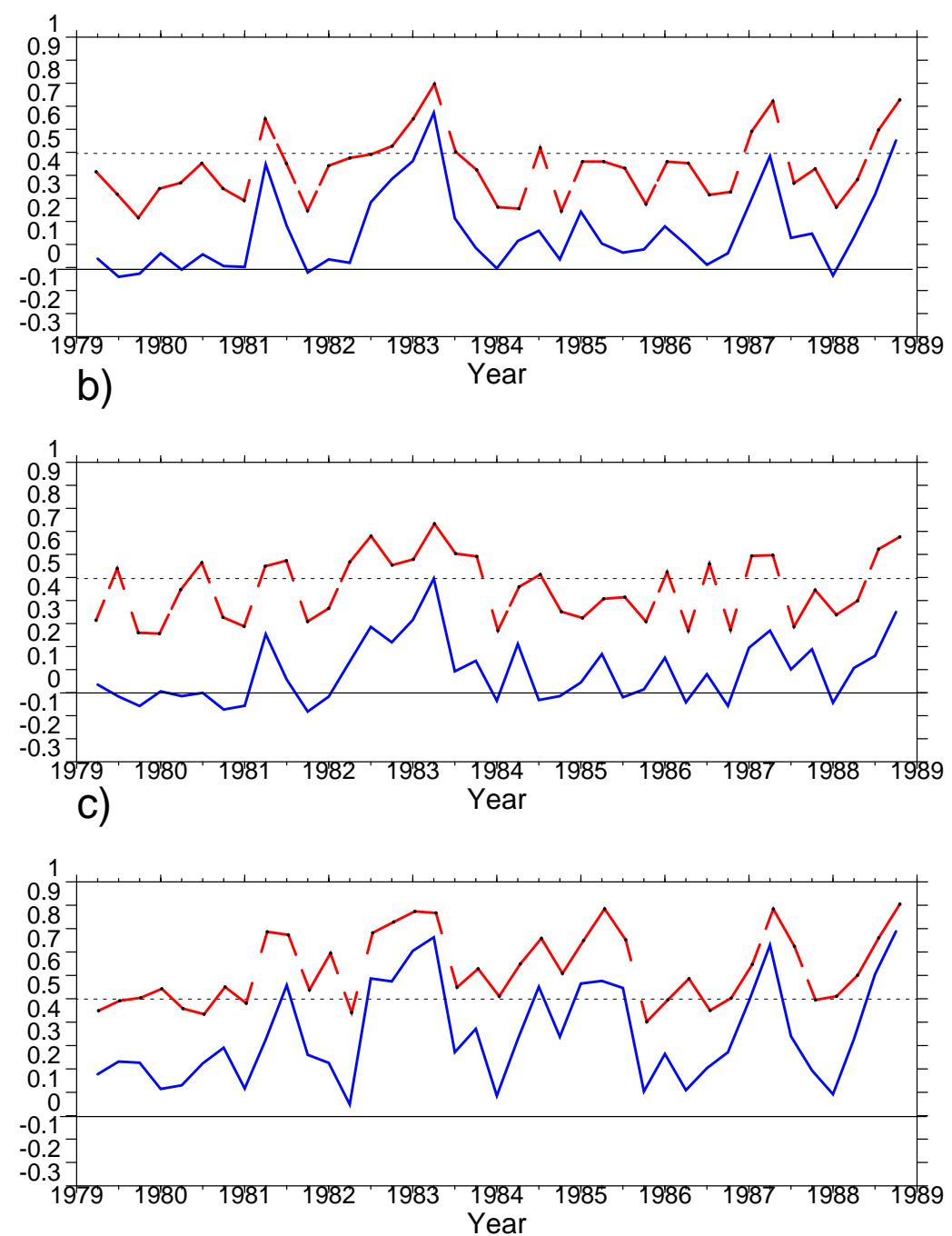

Figure 12: As in Figure 11, except for seasonal anomalies of sea-level pressure. 
a) Mean Sea-Level Pressure

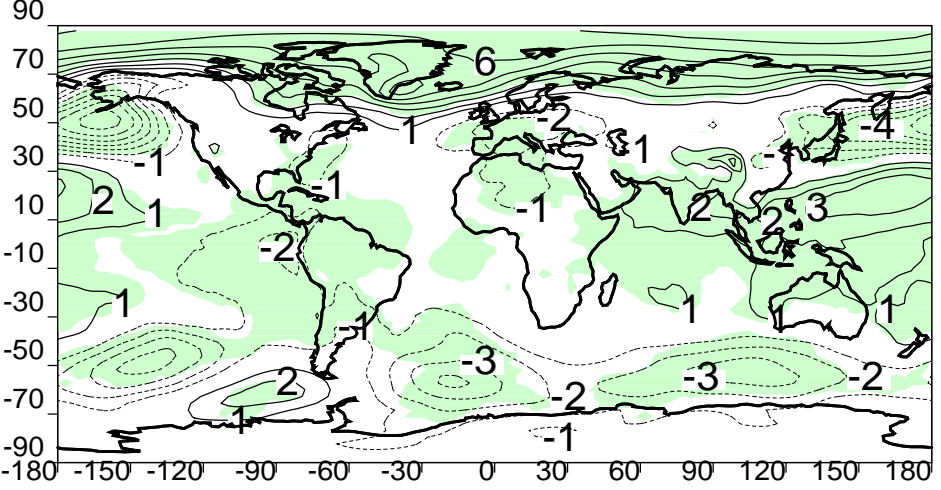

b) Surface Air Temperature

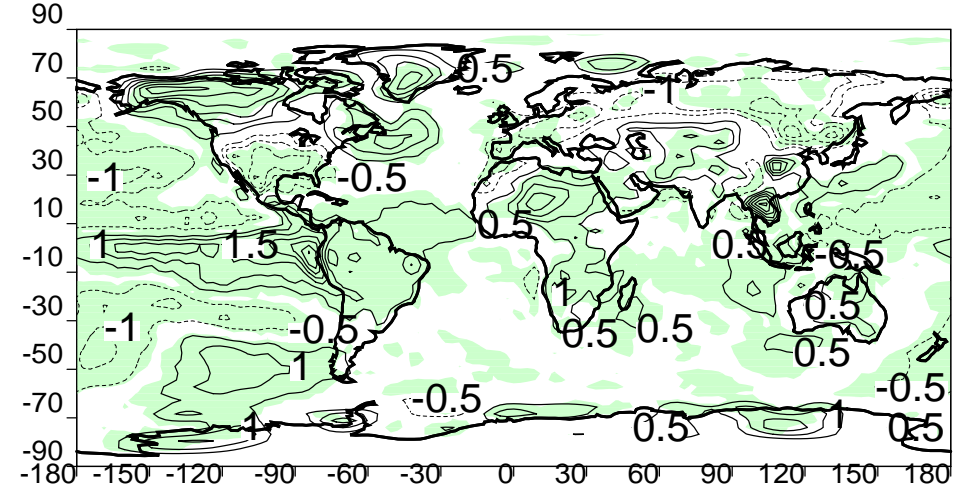

c) Precipitation

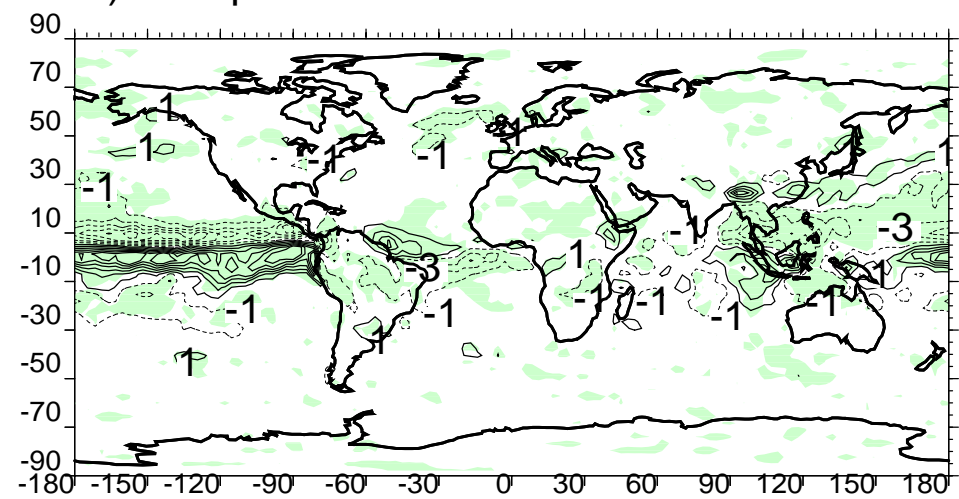

Figure 13: Maps of the average seasonal anomalies (isolines) of a) mean sea-level pressure, b) surface air temperature, and c) precipitation computed across 6 realizations of the season MAM 1983 that coincided with an historically intense El Niño. The shading indicates where these mean anomalies are significantly different (at the $95 \%$ confidence level) from those in the MAM season of the other years of the decade 1979 to 1988 in which an El Niño did not occur (i.e., MAM of all years except 1987). See the text for further explanation. 
a)

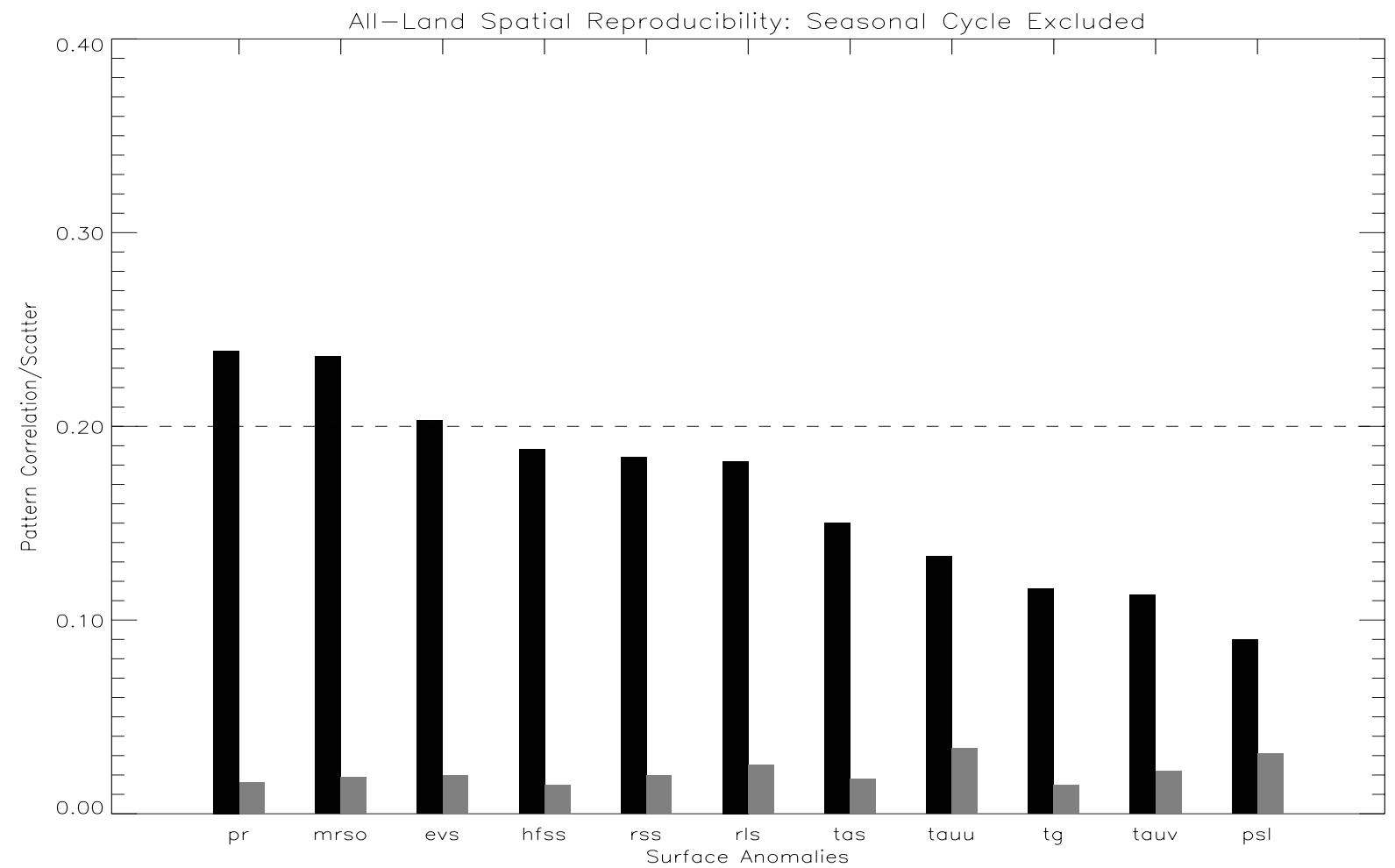

b)

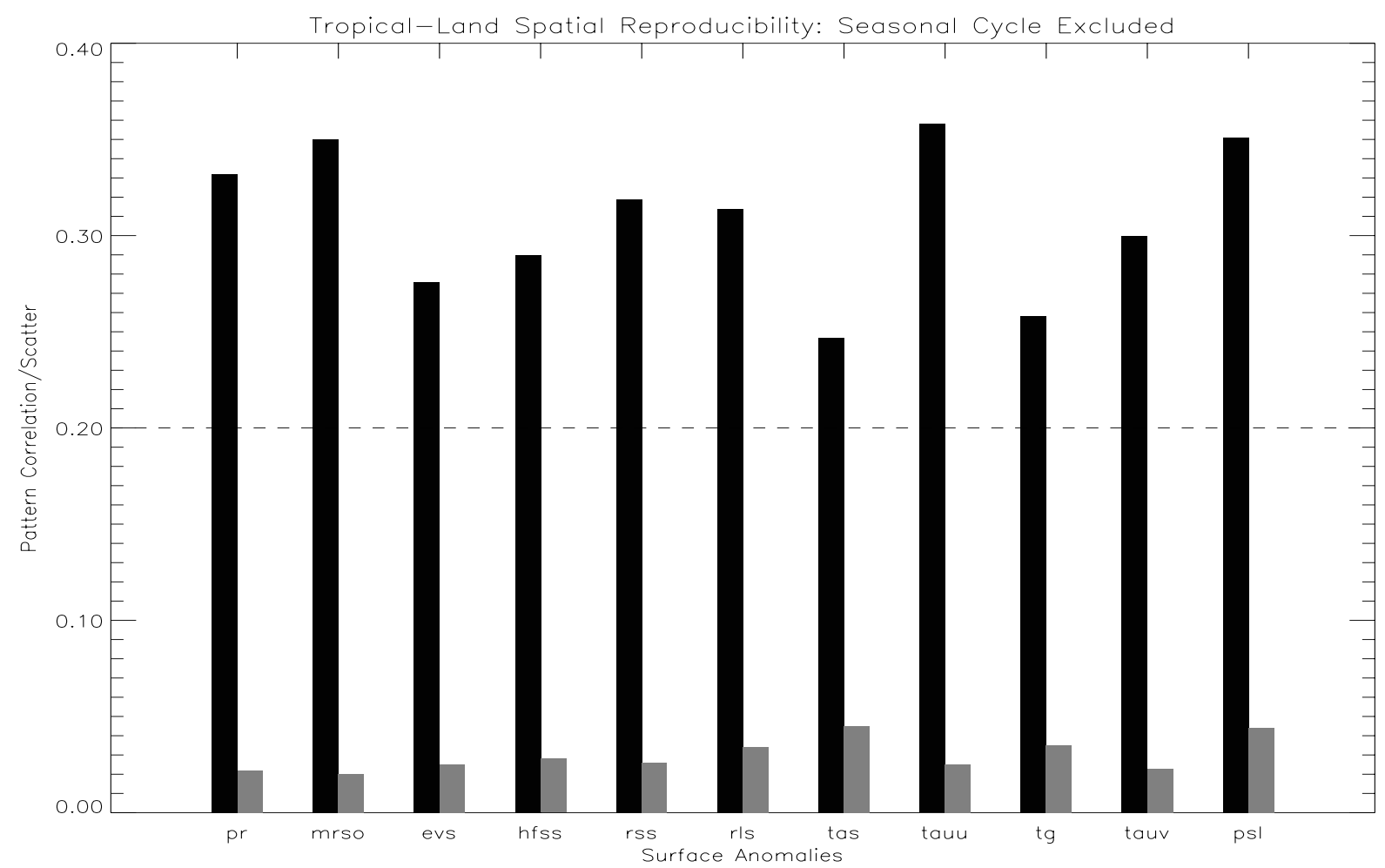

Figure 14: The mean $\mu\{\mathbf{S}\}$ (dark bars) and scatter $\delta\{\mathbf{S}\}$ (gray bars) of the time-average $\mathbf{S}$ of the series of pattern correlations $\mathrm{s}(\mathrm{k})$, season $\mathrm{k}=1, \ldots, 39$ for 11 seasonally averaged ECMWF model surface anomalies are shown, in a) for $\mathrm{s}(\mathrm{k})$ over all land points, and in $\mathrm{b}$ ) for $\mathbf{s}(\mathrm{k})$ only over tropical ( $30 \mathrm{~S}$ to $30 \mathrm{~N})$. The dashed horizontal lines indicate arbitrary reference correlation/scatter values of 0.2. In both panels, the statistics are computed from $\mathrm{N}=15$ independent realizations of the spatial pattern correlations $\mathbf{s}(\mathrm{k})$, and the surface anomalies are arrayed from left to right in descending order of their all-land $\mu\{\mathbf{S}\}$ values in a). 
a)

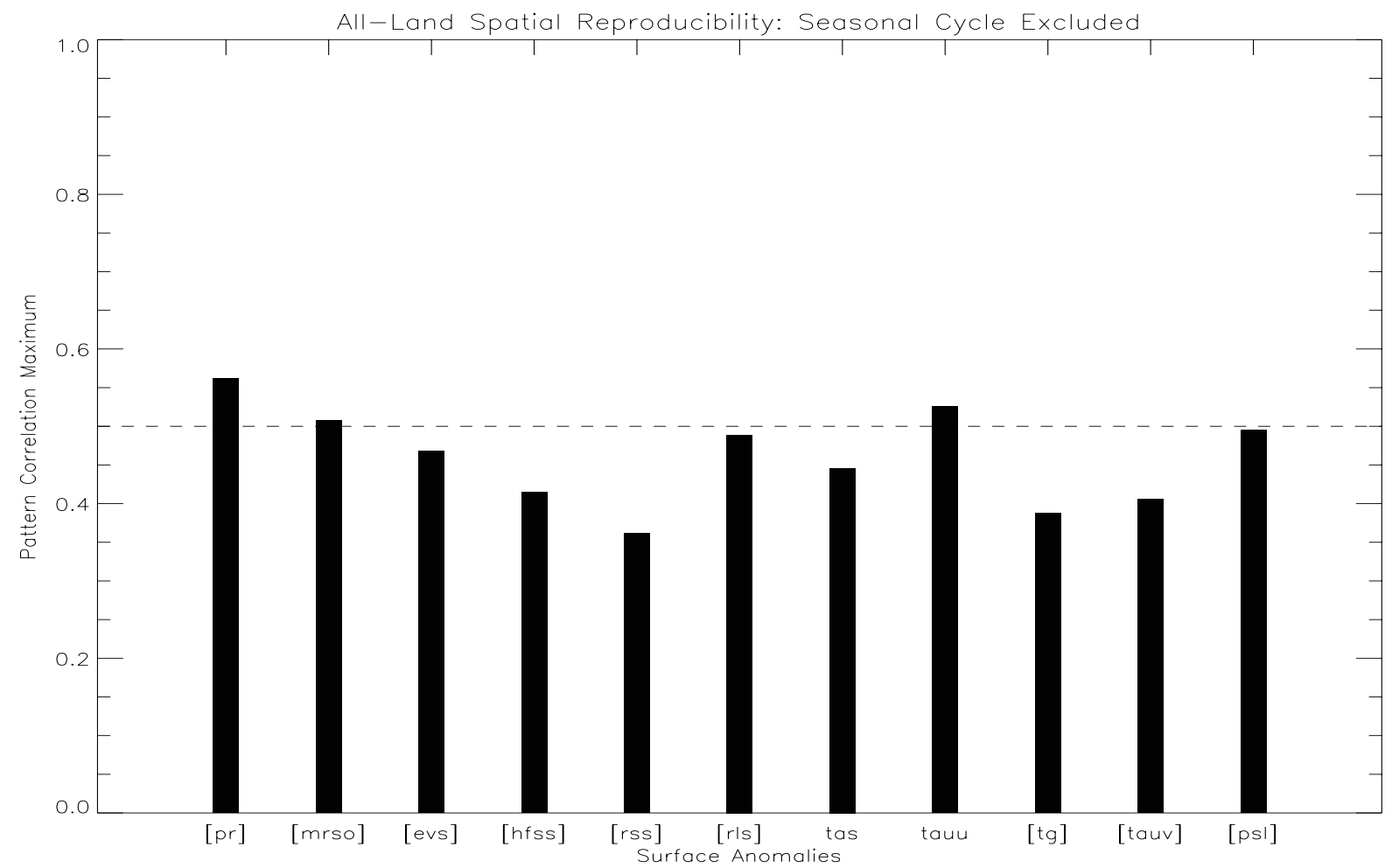

b)

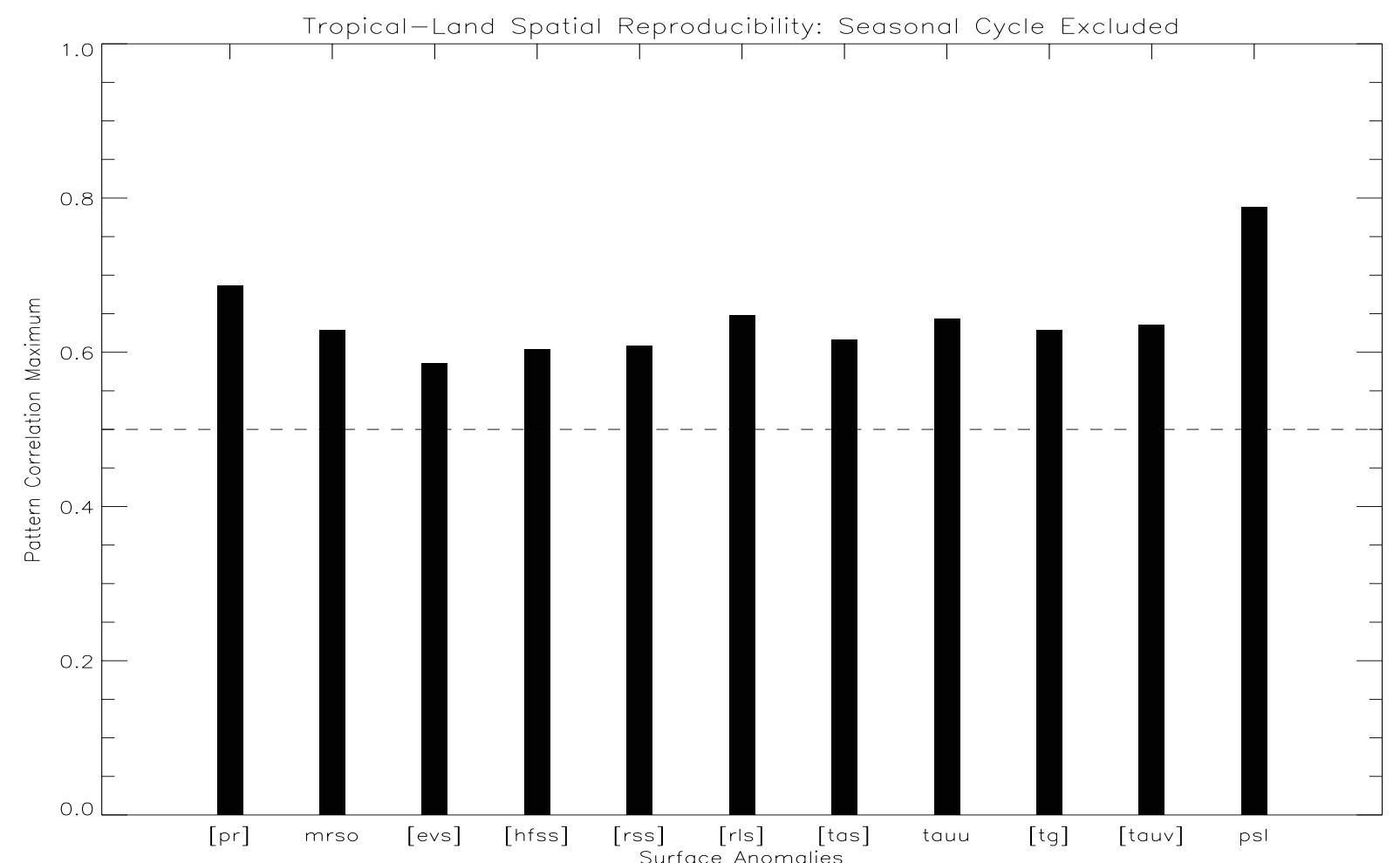

Figure 15: The mean maximum $\mu\{\mathbf{M}\}$ of each anomaly's series of pattern correlations $\mathrm{s}(\mathrm{k})$, season $\mathrm{k}=1, \ldots, 39$ for 11 seasonally averaged ECMWF model surface anomalies are shown, in a) for all-land pattern correlations, and in b) for tropical -land(30S to $30 \mathrm{~N})$ correlations, where the dashed horizontal lines indicate arbitrary common reference $\mu\{\mathbf{M}\}$ values of 0.5 . In a) and b) also, brackets ( [ ] ) surrounding the surface anomaly label indicate coincidence of $\mu\{\mathbf{M}\}$ with the intense 1982/83 El Niño. In both panels, the statistics are computed from $\mathrm{N}=15$ independent realizations of the spatial pattern correlations $\mathbf{s}(\mathrm{k})$, and the surface anomalies are arrayed from left to right in descending order of their allland $\mu\{\mathbf{S}\}$ values, as depicted in Figure 14a). 
a)
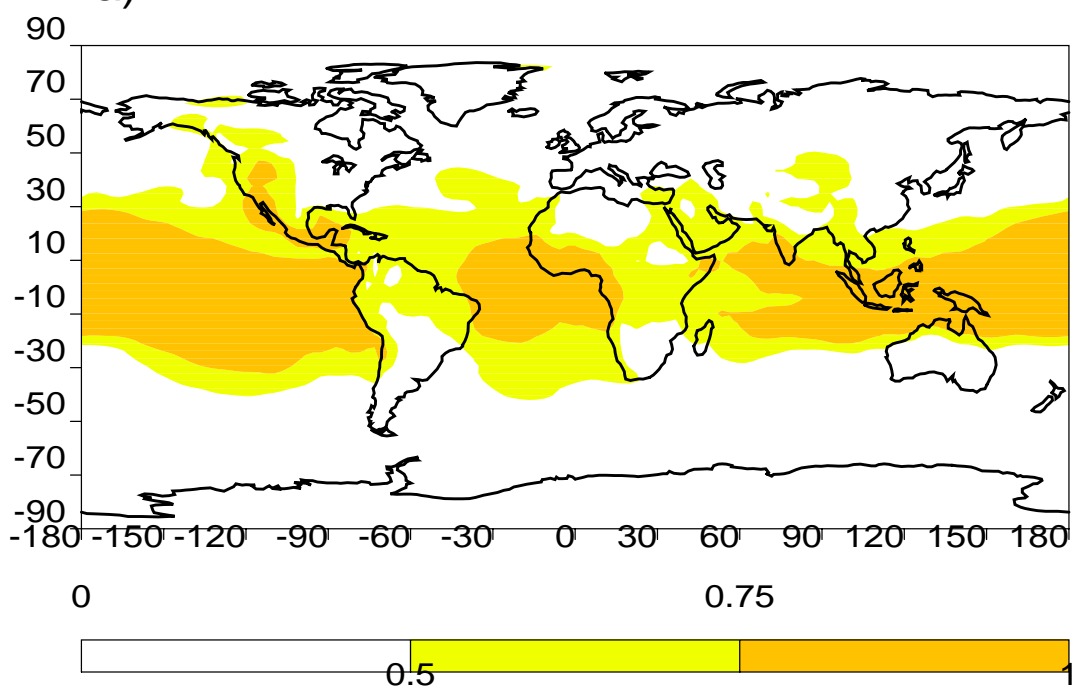

b)

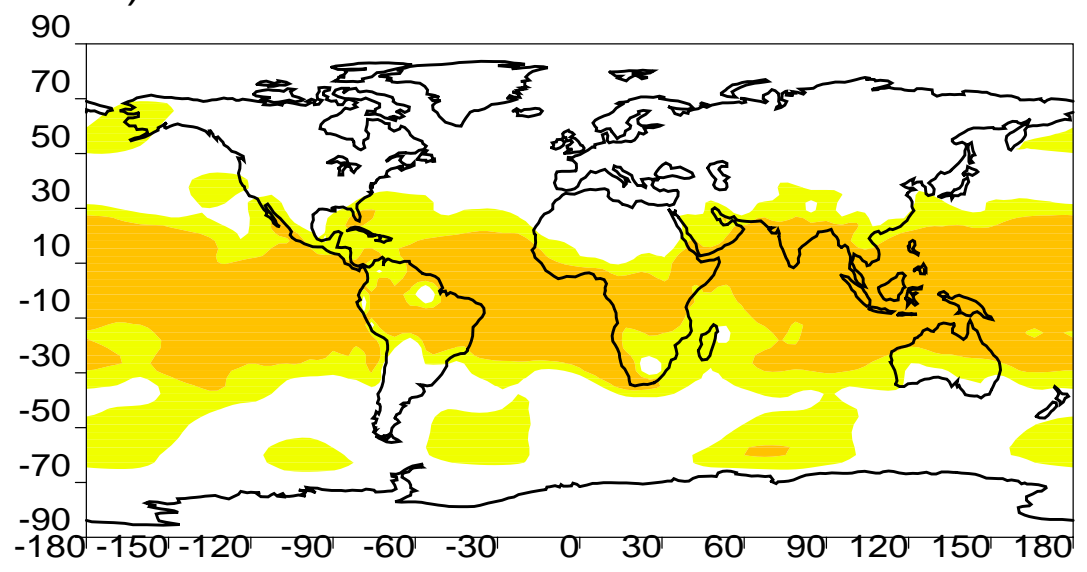

Figure 16: Geographical distribution of the fraction $\mathbf{f}$ of variance of sea-level pressure explained by the common ocean boundary forcing in seasons a) JJA and b) DJF. Shaded areas $\mathrm{f}>0.5$ are indicative of a potentially predictable signal. 
a)

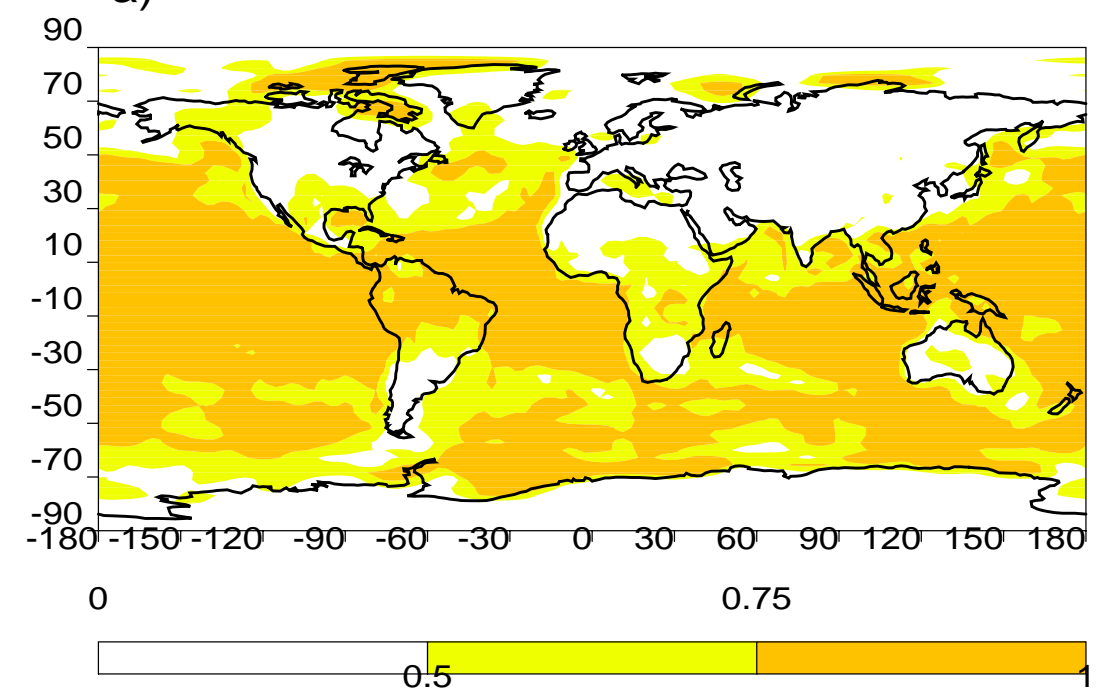

b)

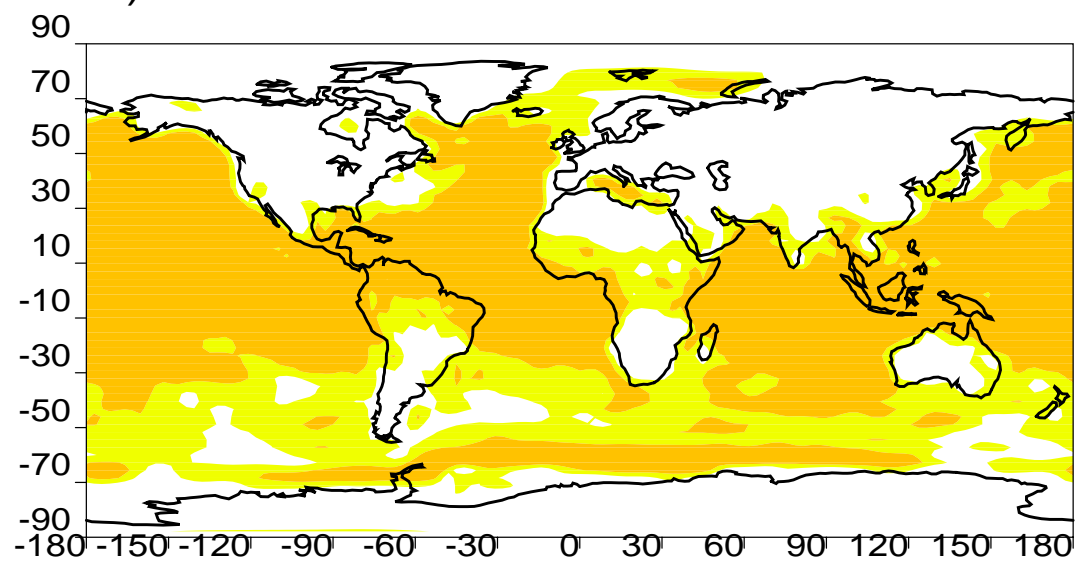

Figure 17: As in Figure 16, except for surface air temperature in seasons a) MAM and b) JJA. 
a)
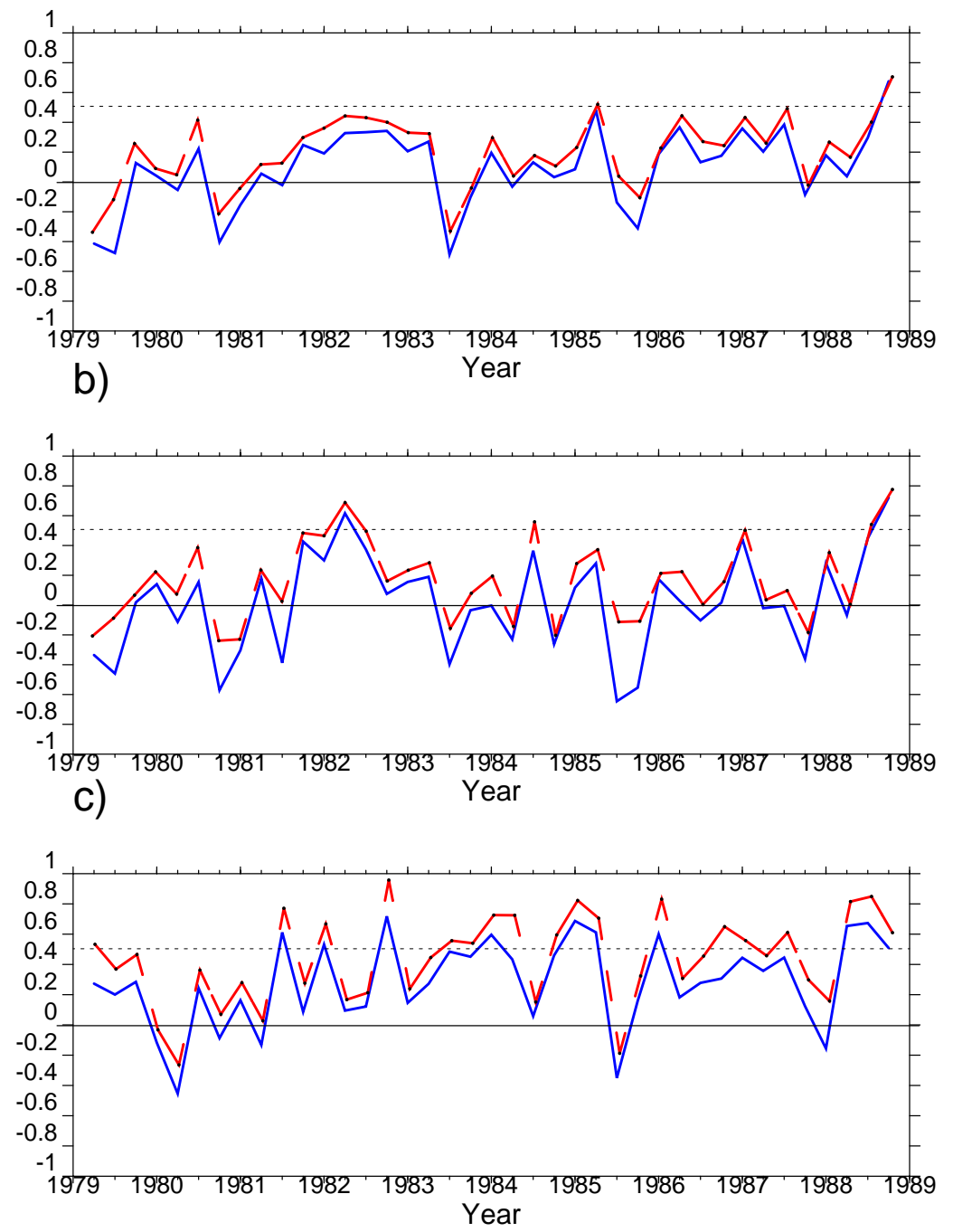

Figure 18: Time series of spatial pattern correlations $\mathbf{c}(\mathrm{k})$ of the ensemble-mean seasonal anomaly of simulated mean sea-level pressure against that from the NCEP-NCAR reanalysis data (in blue) and the estimated uncertainty in $\mathbf{c}(\mathrm{k})$ (in red). The time series includes 39 seasonal samples k, the first at time point MAM of 1979 and the last at time point SON of 1988. (The MAM points are situated just to the right of the major tick marks labeled by each year on the abscissa.) The horizontal dashed lines indicate correlations of 0.5 , which signify a minimum level of practically useful forecast skill. In a) the spatial pattern correlations are computed globally, in b) over all land points, and in c) only over tropical (30 S to $30 \mathrm{~N})$ land points. 
a)
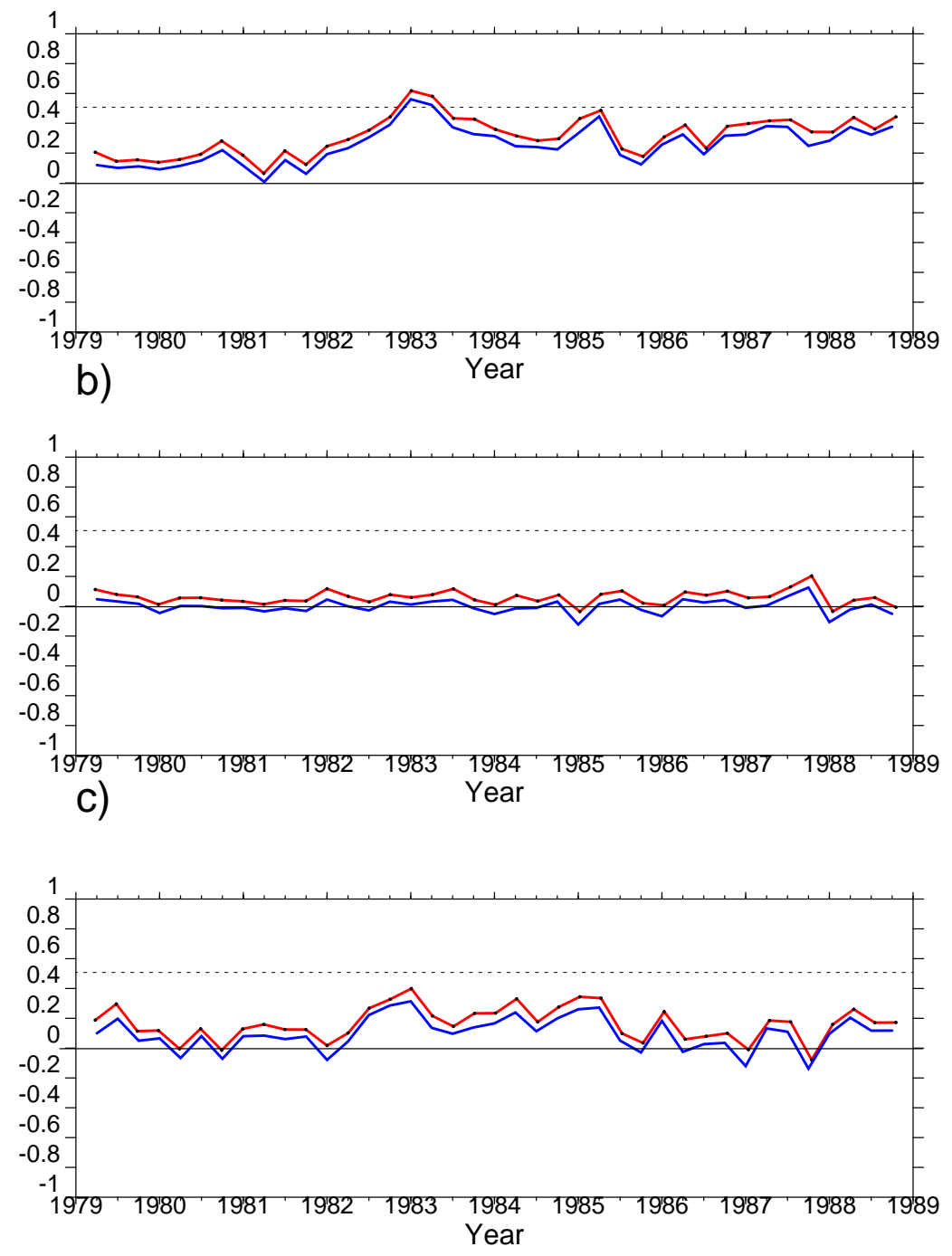

Figure 19: As in figure 18, except for seasonal anomalies of precipitation. 
a)

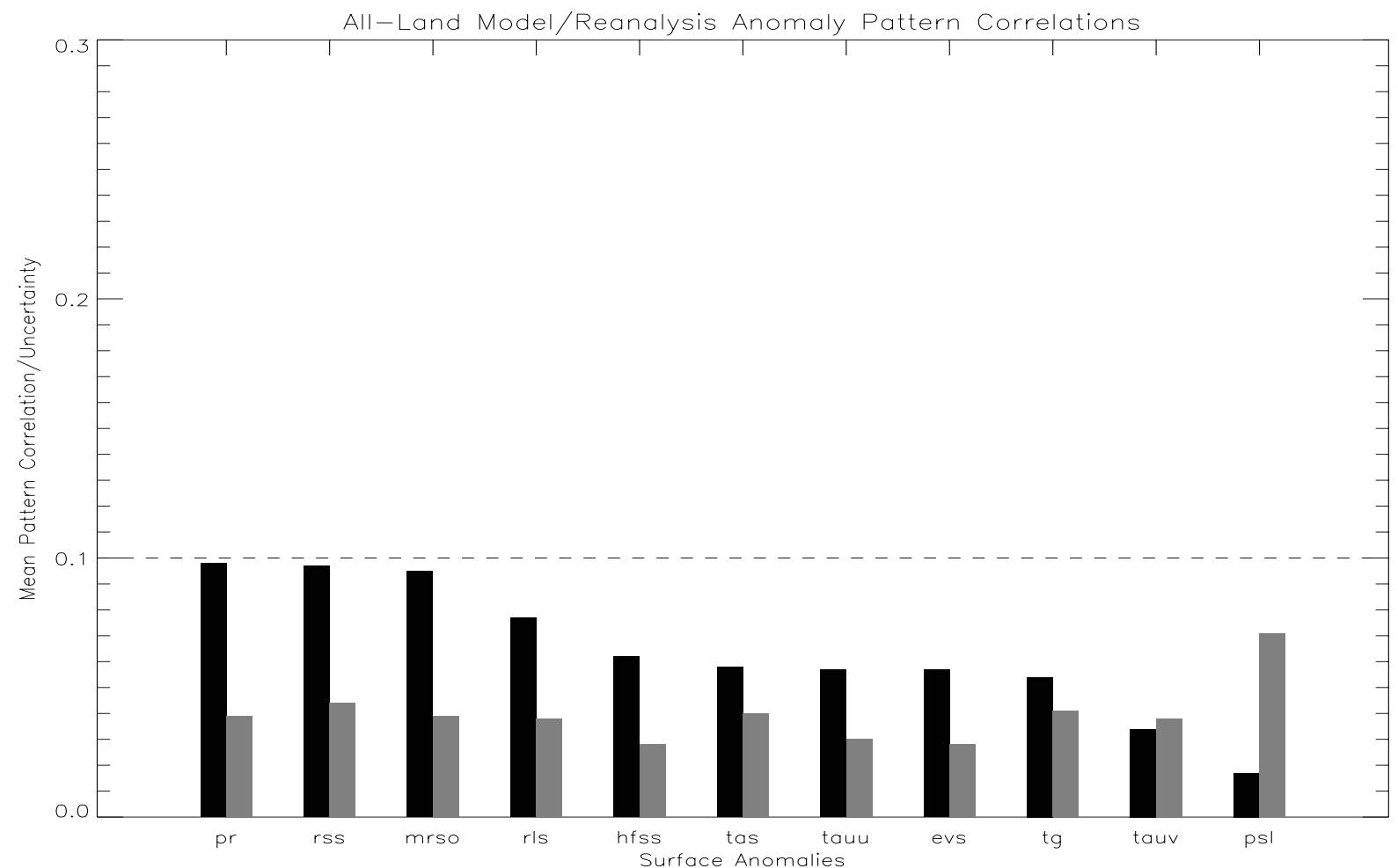

b)

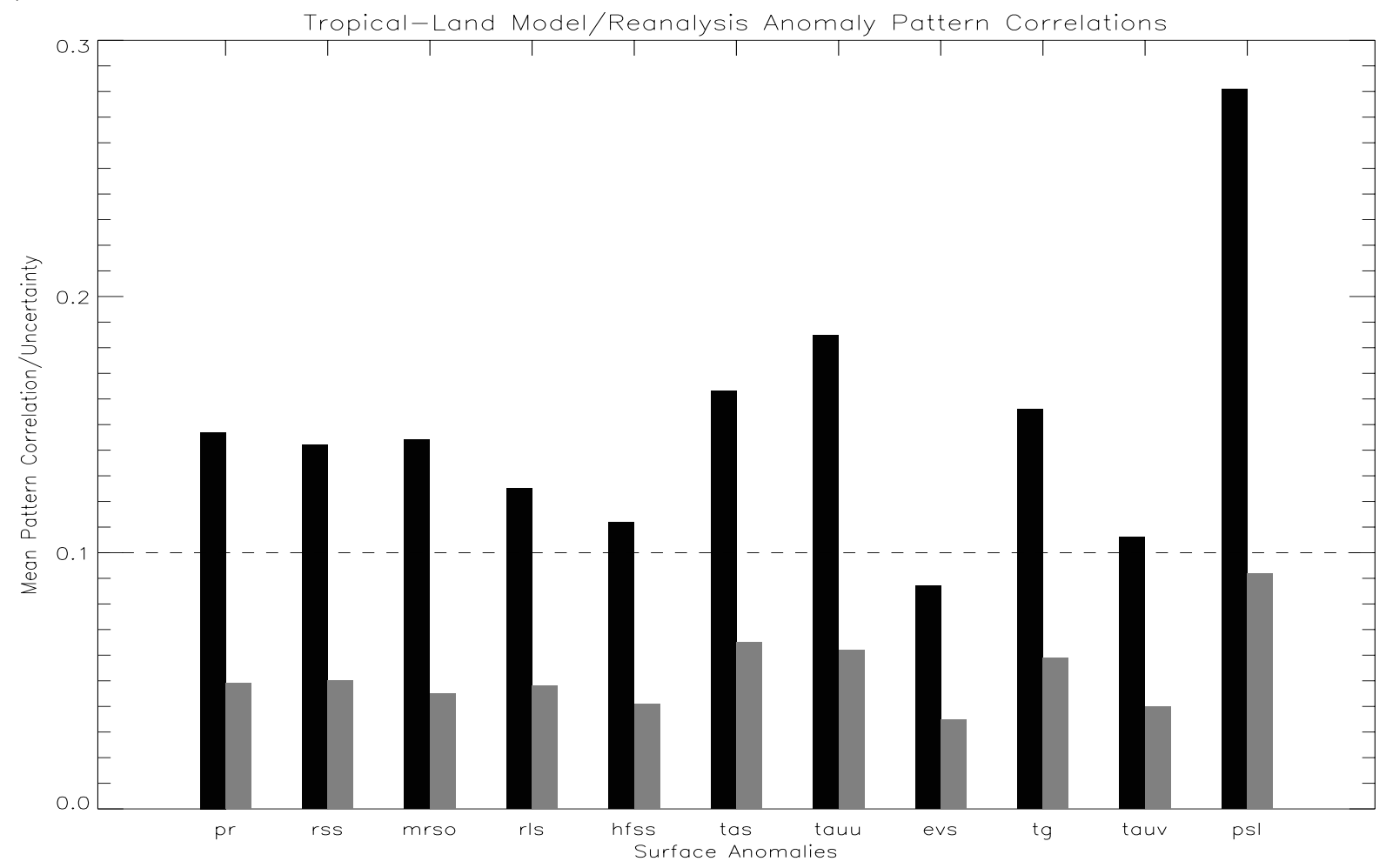

Figure 20: The time-means $\mathbf{C}$ (dark bars) of the series $\mathbf{c}(\mathrm{k})$, season $\mathrm{k}=1, \ldots, 39$ of pattern correlations of the model's ensemble-mean seasonal land-surface anomalies with their counterparts from the NCEP-NCAR reanalysis, along with the estimated uncertainties (gray bars) are shown, in a) for $\mathbf{c}(\mathrm{k})$ over all land points, and in $\mathrm{b}$ ) for $\mathbf{c}(\mathrm{k})$ only over tropical $(30 \mathrm{~S}$ to $30 \mathrm{~N}$ ) land points. As arbitrary common references, the dashed horizontal lines in a) and b) indicate correlation/uncertainty values of 0.1 . In both panels, the statistics are calculated from $n=6$ independent model realizations and from a single realization of the NCEP-NCAR reanalysis, and the surface anomalies are arrayed from left to right in descending order of their all-land $\mathbf{C}$ values, as depicted in a). 
a)

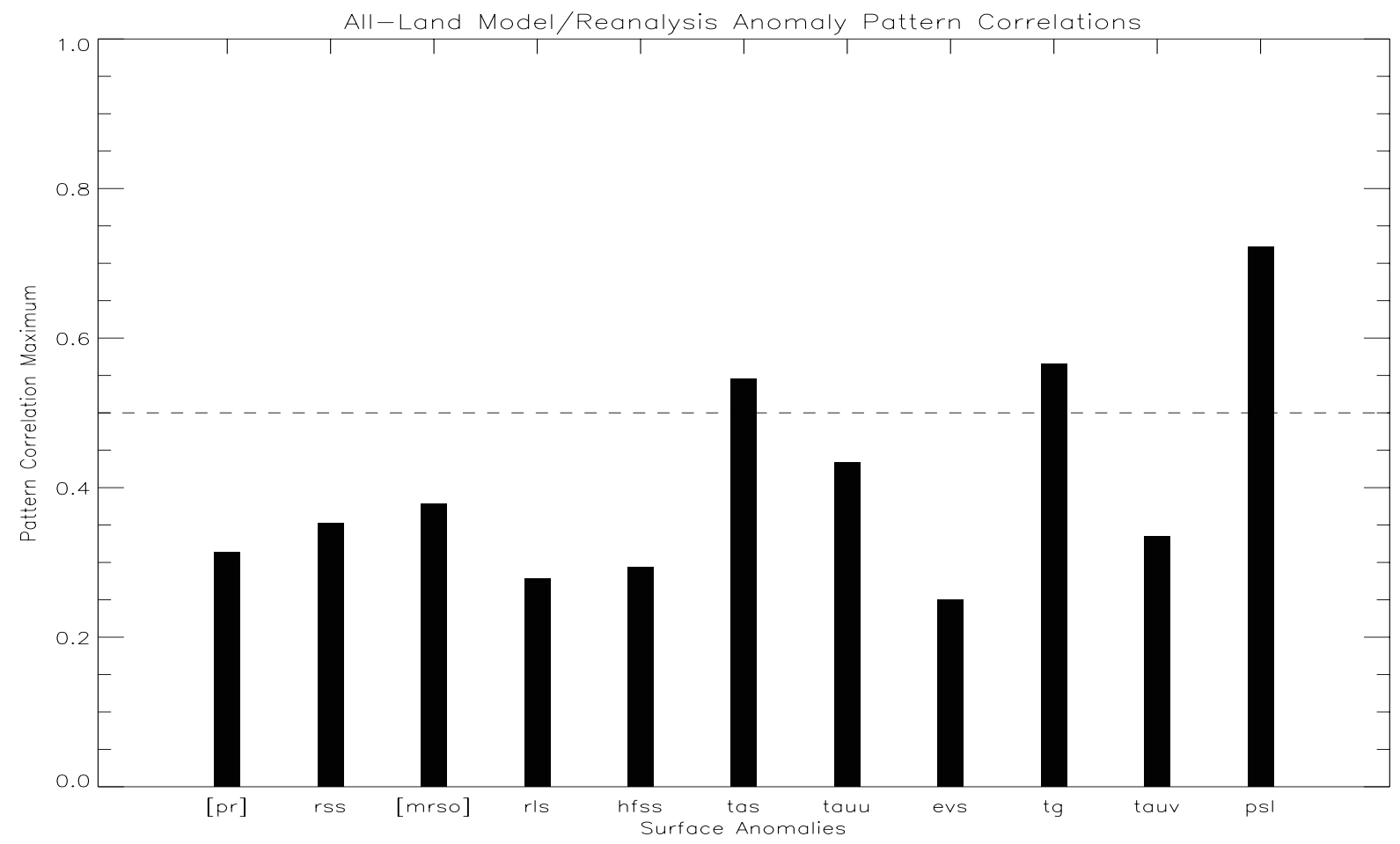

b)

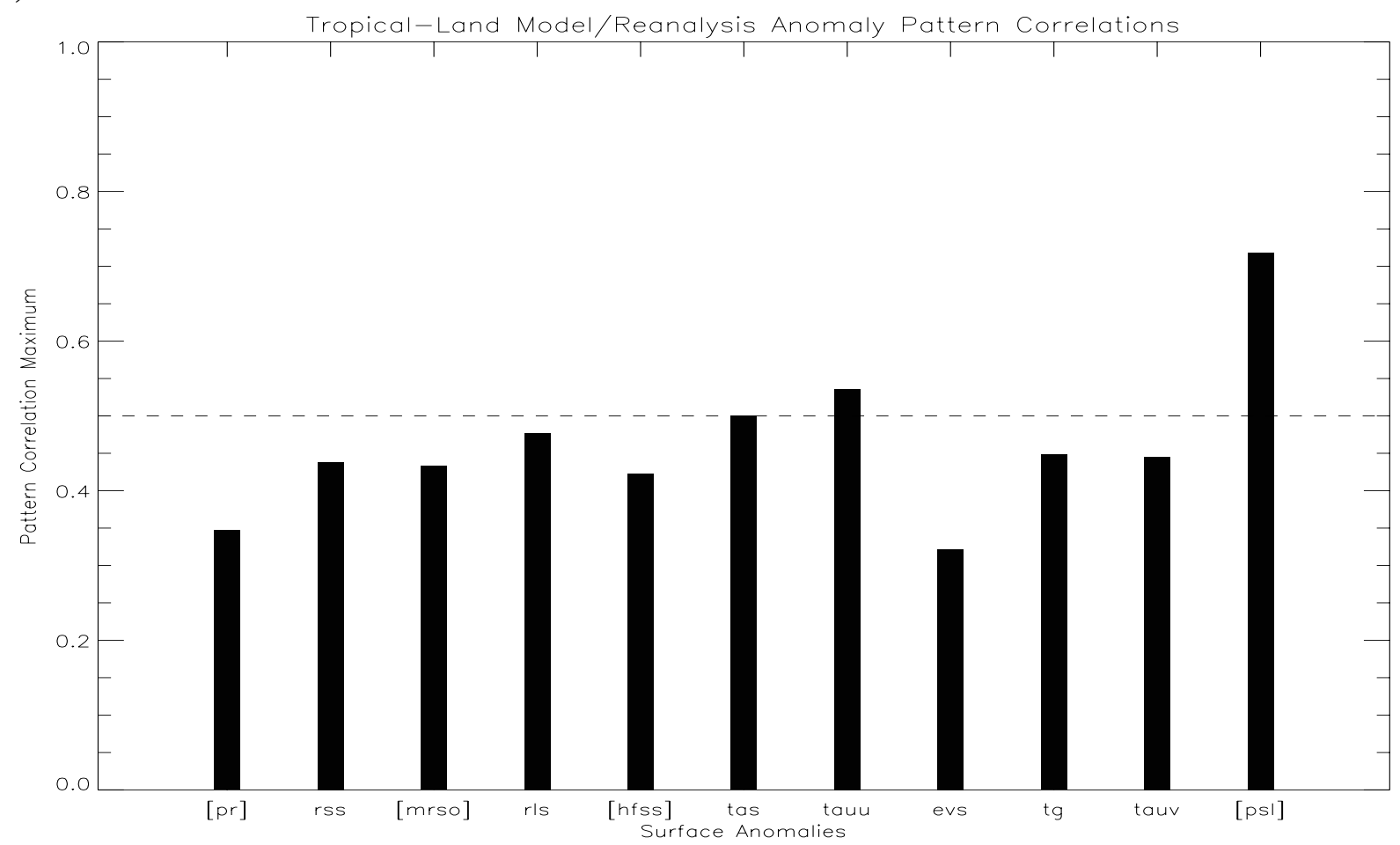

Figure 21: The ensemble-mean maxima $\mathbf{M}$ of the series $\mathbf{c}(\mathrm{k})$, season $\mathrm{k}=1, \ldots, 39$ of pattern correlations of ensemblemean seasonal model land-surface anomalies and their counterparts from the NCEP-NCAR reanalysis are shown, in a) for all-land points, and in b) only for tropical-land ( $30 \mathrm{~S}$ to $30 \mathrm{~N}$ ) points. In a) and b), the dashed horizontal lines indicate anomaly pattern correlations of 0.5 , corresponding to a practically useful level of forecast skill. In both panels also, brackets ( [ ] ) surrounding the surface anomaly label indicate where there is a coincidence of the corresponding maximum $\mathbf{M}$ with the intense 1982/83 El Niño. In both a) and b), the statistics are calculated from $\mathrm{n}=6$ independent model realizations and from a single realization of the NCEP-NCAR reanalysis, and the surface anomalies are arrayed from left to right in descending order of their all-land $\mathbf{C}$ values, as depicted in Figure 20a). 